\title{
A Minimal Anaphase Promoting Complex/Cyclosome (APC/C) in Trypanosoma brucei
}

\author{
Mohamed Bessat, Giselle Knudsen, Alma L. Burlingame, Ching C. Wang*
}

Department of Pharmaceutical Chemistry, University of California San Francisco, San Francisco, California, United States of America

\begin{abstract}
The anaphase-promoting complex/cyclosome (APC/C) is a multi-subunit E3 ubiquitin ligase that initiates chromosome segregation and mitotic exit by targeting critical cell-cycle regulators for proteolytic destruction. Previously, seven APC/C subunit homologues were identified in the genome of Trypanosoma brucei. In the present study, we tested five of them in yeast complementation studies and found none of them capable of complementing the yeast mutants lacking the corresponding subunits, suggesting significant discrepancies between the two APC/C's. Subunit homologues of mitotic checkpoint complex (MCC) have not yet been identified in T. brucei, raising the possibility that a MCC-APC/C complex equivalent may not exist in T. brucei. We performed tandem affinity purification of the protein complex containing a APC1 fusion protein expressed in the cells enriched in different phases of the cell cycle of procyclic form T. brucei, and compared their protein profiles using LC-MS/MS analyses. The seven putative APC/C subunits were identified in the protein complex throughout the cell cycle together with three additional proteins designated the associated proteins (AP) AP1, AP2 and AP3. Abundance of the 10 proteins remained relatively unchanged throughout the cell cycle, suggesting that they are the core subunits of APC/C. AP1 turned out to be a homologue of APC4. An RNAi knockdown of APC4 and AP3 showed no detectable cellular phenotype, whereas an AP2 knockdown enriched the cells in G2/M phase. The AP2-depleted cells showed stabilized mitotic cyclin B. An accumulation of poly-ubiquitinated cyclin B was indicated in the cells treated with the proteasome inhibitor MG132, demonstrating the involvement of proteasome in degrading poly-ubiquitinated cyclin B. In all, a 10-subunit APC/C machinery with a conserved function is identified in T. brucei without linking to a MCC-like complex, thus indicating a unique T. brucei APC/C.
\end{abstract}

Citation: Bessat M, Knudsen G, Burlingame AL, Wang CC (2013) A Minimal Anaphase Promoting Complex/Cyclosome (APC/C) in Trypanosoma brucei. PLoS ONE 8(3): e59258. doi:10.1371/journal.pone.0059258

Editor: Ziyin Li, University of Texas Medical School at Houston, United States of America

Received January 10, 2013; Accepted February 13, 2013; Published March 22, 2013

Copyright: (c) 2013 Bessat et al. This is an open-access article distributed under the terms of the Creative Commons Attribution License, which permits unrestricted use, distribution, and reproduction in any medium, provided the original author and source are credited.

Funding: This work was supported by National Institutes of Health R01 grant R01 Al21786 to CCW. The funders had no role in study design, data collection and analysis, decision to publish, or preparation of the manuscript.

Competing Interests: The authors have declared that no competing interests exist.

*E-mail: ccwang@cgl.ucsf.edu

\section{Introduction}

Trypanosoma brucei, is an early divergent protozoan parasite that causes African sleeping sickness in human and nagana in livestock. It has a complex biphasic life cycle that allows the cells to multiply in both the mammalian host and the insect vector tsetse flies [1]. There are many unique features in the cell cycle progression in $T$. brucei when compared with that in metazoa [2,3]. For instance, cytokinesis in the bloodstream-form $\mathrm{T}$. brucei is controlled by mitosis whereas that in the insect (procyclic) form is driven primarily by the duplication and segregation of basal bodies and its associated mitochondrial DNA complexes, the kinetoplasts $[4,5,6]$. Therefore, procyclic form cells can undergo cytokinesis in the absence of mitosis, whereas a mitotic arrest in bloodstream form cells inhibits cytokinesis with continued kinetoplast replication and segregation and nuclear DNA synthesis $[2,5,6]$, which implicates fundamental differences in cell cycle controls between different life cycle forms of $T$. brucei and potential absence of the key cell cycle checkpoints. Cell division in both forms of $\mathrm{T}$. brucei proceeds longitudinally along the dorsal line from the anterior to the posterior end of the cell [7], which contrasts significantly from that in metazoa $[8,9]$. The mechanism of this distinctive form of cell division in $T$. brucei is initiated by a trans-localization of the chromosome passenger complex (CPG) from the midzone of central spindle across the nuclear envelope to the flagellar attachment zone (FAZ) during the final stage of mitosis [10]. The CPC then moves along the FAZ to the anterior end of the dividing cell and slides back toward the posterior end along the FAZ in an unzipping action to separate the dividing mother from the daughter [10]. The cell cycle of T. brucei has thus become one of the most intriguing subjects for further investigation in recent years.

The progression from metaphase to anaphase during mitosis of $\mathrm{T}$. brucei appears, however, somewhat similar to that observed in other eukaryotes [2]. The chromosomes in the nucleus of T. brucei are replicated during S-phase and attached to the mitotic spindle and aligned in two closely associated parallel rows during metaphase [11]. The chromosomal duplexes are then pulled apart by the mitotic spindle into two separate entities during anaphase [1 1]. Metaphase-anaphase transition and mitotic exit in metazoa and yeast are controlled primarily by the anaphase promoting complex/cyclosome (APG/C) regulated by periodic association and dissociation with the mitotic checkpoint complex (MCG). APC/C is a multi-subunit E3 ubiquitin ligase consisting of 13 core subunit proteins in yeast that is inactivated by association with the effector proteins of the MCC complex in the prometaphase $[12,13,14,15,16]$. When proper alignment and attachment of the duplicated chromosomes to the mitotic spindle 
are achieved toward the end of metaphase, MCG and APC/C are dissociated from each other leaving a single MCG subunit protein, CDC20, with the APG/C to activate the latter to polyubiquitinate securin/Pds1 for $26 \mathrm{~S}$ proteasomal degradation $[17,18,19]$. Securin/Pdsl inhibits the activity of a protease separase by binding to the latter during metaphase. Upon its destruction, separase is freed and activated and degrades the cohesin protein binding the sister chromatids for successful chromosome segregation and cell cycle progression to the anaphase [20]. Toward the late mitotic phase, a mitotic cyclin B is targeted by the activated APC/C for poly-ubiquitination and subsequent $26 \mathrm{~S}$ proteasome-mediated degradation thus lowers the activity of cyclin-dependent kinas 1 (CDK1) for mitotic exit $[21,22]$.

In our previous study, we identified seven APG/C subunit homologues in T. brucei that include APG1, APC2, APG10/ DOC1, APC1 1, CDC16, CDC23 and CDC27 [23]. There is also a CDC20 and a separase homologue found in T. brucei genome database (unpublished data and [24]). But no homologue of securin/Pds1 or any of the MCG subunit proteins has yet been identified in this organism. The separase homologue demonstrated a conserved role in catalyzing chromosome segregation in T. brucei [24], but an RNAi knockdown of CDC20 in procyclic form T. brucei showed no apparent mitotic arrest (unpublished data). Further RNAi knockdowns of each of the seven subunit proteins in the apparent APC/C of T. brucei showed that only depletion of APC1 or CDC27 resulted in mitotic arrest in both procyclic and bloodstream form cells [23], whereas knockdowns of the rest of the 5 subunits showed no apparent phenotype [23]. This outcome is similar to that from Saccharomyces cerevisiae, in which mutants of APC9 [25], MND2, SWM1 [26] or CDC26 [27] did not register any phenotype and were classified as the nonessential subunits of the $\mathrm{APC} / \mathrm{C}$ in yeast.

There is thus a likely presence of functional APG/C in $\mathrm{T}$. brucei [23]. But the previous results did not verify whether the 7 subunits constitute the entire core of a APC/C structure or if more protein subunits are involved in constituting the complex. Nor is it clear if the APC/C function is regulated by associating with a functional MCC-like complex or whether a functional homologue of securin/Pdsl and a functional homologue of CDC20 may exist and play pivotal roles in metaphase-anaphase transition in $\mathrm{T}$. brucei.

In an effort to clarify these issues, we first used the method of yeast complementation to examine if any of the putative T. brucei $\mathrm{APC} / \mathrm{C}$ subunits are capable of replacing those in S. cerevisiae, and found that among those tested, none was capable of substituting the yeast counterpart. We then used tandem affinity purification (TAP) and mass spectrometry to identify the composition of $\mathrm{T}$. brucei $\mathrm{APC} / \mathrm{C}$ and examined its potential association-dissociation with other proteins during the metaphaseanaphase transition. The outcome indicated that, throughout the entire cell cycle, there was a constant presence of an apparent APC/C complex consisting of 10 subunit proteins. Neither the CDC20 homologue nor any other protein was found detectable with the $\mathrm{APC} / \mathrm{C}$ at any phase of the cell cycle, suggesting a unique mechanism of APG/C regulation in T. brucei. The mitotic cyclin B of T. brucei (cycB2/cyc6) [28] was, however, found polyubiquitinated by the APC/C and degraded by proteasome for mitotic exit as in other eukaryotes.

\section{Materials and Methods}

\section{Yeast Complementation Assay}

Temperature-sensitive (ts) S. cerevisiae mutants cdc16-1, cdc231, cdc27-1 and apc1-1 were kindly provided by Dr. D. Toczyski of UCSF [29]. The apc10-1 ts mutant was purchased from Open Biosystems (Thermo Scientific). A wild-type 303wt strain of $\mathrm{S}$. cerevisiae was from Dr. P. Walter of UCSF. The genetic background among the yeast strains are all of Mat/a except for the apc10-1 mutant and 303 wt strain, which are of Mat/ $\alpha$. For the standard yeast propagation, cells were grown in Yeast extract/ Peptone/Dextrose (YPD) medium. Full-length open reading frames (ORFs) of genes encoding CDC16, CDC23, CDC27, APC1 and APC10/DOC1 were amplified from the yeast and the T. brucei genomic DNAs by PCR using gene specific primers with restriction sites for cloning into the yeast expression plasmid, pRS416-ADH [30]. Individual constructs were introduced into the corresponding yeast mutants and expressed under the control of yeast specific $\mathrm{ADH}$ promoter [30]. The transformed cells were selected on the synthetic-defined (SD) minimal selection medium supplemented with the Drop-Out (DO) supplement-Ura (Clontech). Yeast transformation and selection were by the protocol of Gietz $[31,32]$. Replica plates of transformed cells were incubated for 3 days at either the permissive $\left(25^{\circ} \mathrm{C}\right)$ or the restrictive $\left(37^{\circ} \mathrm{C}\right)$ temperature for indication of genetic complementation by the cloned genes.

\section{Trypanosome Cell Culture}

Procyclic-form T. brucei cells of the wild type strain 427 and the modified strain 29-13 for RNAi studies [33] were both cultivated at $26^{\circ} \mathrm{C}$ in the Cunningham medium supplemented with $10 \%$ fetal bovine serum (Hyclone. Thermo scientific, USA). For the 29-13 strain, $15 \mu \mathrm{g} \mathrm{ml}^{-1} \mathrm{G} 418$ and $50 \mu \mathrm{g} \mathrm{ml}^{-1}$ hygromycin B were added to the culture medium to maintain expression of T7 RNA polymerase and tetracycline repressor, respectively [33]. Cell densities were maintained at the mid-log phase of $\sim 5 \times 10^{6}$ cells $\mathrm{ml}^{-1}$ through regular subculturings. Transfection and selection of the procyclic $T$. brucei cells were carried out as described previously [34].

\section{Expression of Protein A-tobacco Etch Virus (TEV) Protease Site-protein C Epitope (PTP)-tagged APC1 and Purification of the APC1-associated Protein Complex}

The 3 '-terminal fragment of T. brucei APCl gene encompassing nucleotide sequence \#4,668-\#5,510 was amplified by PCR from the genomic DNA of the cells of 427 strain and cloned in frame into the pC-PTP-NEO plasmid to produce the pC-APC1PTP construct [35]. The plasmid was linearized with $\mathrm{XcmI}$ and transfected into the strain 427 cells by electroporation for genome integration through homologous recombination. The transfected cells were selected under $40 \mu \mathrm{g} \mathrm{ml}^{-1}$ G418. Correct PTP tagging of the endogenous APCl gene in the transfected cells was subsequently confirmed with PCR and DNA-sequencing. The transfected cell cultures were further diluted and distributed to 24well plates at a calculated average of a single cell per well for further cell growth to identify the cloned cell line [36]. The cells showing consistent and optimal growth rates were selected and tested for expression of the PTP-tagged APC1 protein in Western blotting (see below) and stored in liquid nitrogen.

For purification of the PTP-APG1-containing protein complex from the cloned transfected cells, crude lysate was prepared from $\sim 1 \times 10^{9}$ cells by sonication, and cleared by a brief centrifugation [35]. The cell lysate was then subjected to stepwise purifications through immunoglobulin $\mathrm{G}(\mathrm{IgG})$ column binding, TEV protease 
elution, protein $\mathrm{C}$ antibody column binding and EGTA chelating elution according to the established procedure [35]. Each step of the purification was monitored with Western blotting and SDSPAGE stained with SYPRO Ruby (Invitrogen, CA). Individual protein bands in the final purified sample fractionated in SDSPAGE and stained with SYPRO Ruby were sliced from the gel, diced and processed for in-gel trypsin digestion by a standard protocol (The UCSF Mass Spectrometry In-gel digestion procedure@ms-facility.ucsf.edu/ingel.html) followed by mass spectrometric analysis (see below).

\section{Synchronization of the Cell Cycle Progression in T. brucei}

Mid-log phase procyclic-form T. brucei cells expressing APC1PTP were treated with $0.3 \mathrm{mM}$ of hydroxyurea and incubated at $26^{\circ} \mathrm{C}$ for $16 \mathrm{hr}$ to become synchronized in the late $\mathrm{S}$ phase [37]. Hydroxyurea was then washed off, and the late $\mathrm{S}$ phase cells were cultivated for synchronized cell cycle progression for 2.5 additional hrs for a cell population highly enriched in metaphase, and $4.5 \mathrm{hrs}$ to enrich the cells in anaphase [10]. The unsynchronized cells are enriched in G1 phase. They and the other cell populations enriched in $\mathrm{S}$ phase, metaphase and anaphase were each used for the TAP purification of APC1-associated protein complexes and for comparisons of their protein profiles in SDS-PAGE-SYPRO Ruby gels and mass spectrometric analysis.

\section{Liquid Chromatography-tandem Mass Spectrometry (LC- MS/MS)}

Following in-gel trypsin digestions, samples from individual protein bands were each analyzed using an LTQ-Orbitrap XL (Thermo) mass spectrometer. It was equipped with a 10,000 psi system nanoACUITY (Waters) UPLC instrument for peptide separation by reversed phase chromatography with a C18 column (BEH130, $1.7 \mu \mathrm{m}$ bead size, $100 \mu \mathrm{m} \times 100 \mathrm{~mm}$ ). The LG was operated at a flow rate of $600 \mathrm{~nL} / \mathrm{min}$, and the peptides were separated using a linear gradient of acetonitrile from $2 \%$ to $30 \%$ in solvent A $(0.1 \%$ formic acid in water $)$ and solvent $\mathrm{B}(0.1 \%$ formic acid in $70 \%$ acetonitrile) over a period of $42 \mathrm{~min}$. Survey scans were recorded over $310-1600 \mathrm{~m} / \mathrm{z}$ range, and MS/MS was performed in data dependent acquisition mode with CID fragmentation on the six most intense precursor ions, measured in the ion trap.

Lists of mass spectrometric peaks were generated using the inhouse software PAVA, and data were searched using the Protein Prospector software v. 5.10 .0 [38]. Database searches were performed against the SwissProt database (downloaded March 21, 2012) to which was added the $T$. brucei subset of the TriTrypDB database v. 4.1 (downloaded June 21, 2012) totaling 563,498 entries. For estimation of false discovery rates, the database was concatenated with a fully randomized set of sequence entries [39]. Data were searched with mass tolerances of $20 \mathrm{ppm}$ for parent and 0.6 Da for fragment ions.

For database searching, peptide sequences were matched as tryptic peptides with no missed cleavages, and carbamidomethylated cysteines as a fixed modification. Variable modifications included oxidation of methionine, $\mathrm{N}$-terminal pyroglutamate from glutamine, loss of methionine and $\mathrm{N}$-terminal acetylation. Protein Prospector score parameters were set at a minimum protein score of 22, minimum peptide score of 15 , and maximum expectation values of 0.01 for protein and 0.001 for peptide matches, resulting in a protein false discovery rate of $0.4 \%$. Protein identification results from specific TAP experiments were reported with a spectral count as an approximation of protein abundance, along with percent sequence coverage and an expectation value for the probability of protein identification [40,41].

\section{RNA Interference}

Target gene fragments were selected based on default settings of the RNAit software [42]. They were amplified from the strain 2913 genomic DNA with PCR using sense primer carrying flanking BamHI/HindIII sites and antisense primer carrying flanking XhoI/XbaI sites for cloning the individual fragments into the Stem-loop pALC14 plasmid [24,43]. The constructs were linearized with NotI and transfected into 29-13 procyclic cells via electroporation [34]. The transfected cells were cultivated for 15 to 18 days, and the stable transfectants were selected in the presence of $1 \mu \mathrm{g} \mathrm{ml} \mathrm{g}^{-1}$ puromycin. Clonal cell lines were established by limiting dilution and cultivation in 24-well plate. The cloned stable transfectants that reached a constant growth rate after at least three regular passages were selected and tested for RNAi phenotypes. To induce RNAi, $1 \mu \mathrm{g} \mathrm{ml}{ }^{-1}$ tetracycline was added to the culture of a cell density of $2 \times 10^{5} \mathrm{cells} \mathrm{ml}^{-1}$. Cell growth was monitored by counting the cell numbers with a haemocytometer at $24 \mathrm{hr}$ intervals. For RNA extraction and cell cycle analysis, $24 \mathrm{hr}$ cell samples after RNAi induction were collected, washed once with PBS and processed for either RNA extraction using the TRIzol ${ }^{\circledR}$ reagent (Invitrogen) or cell cycle analysis in flow cytometry (see below).

\section{Quantitative Real-time RT-PCR (qRT-PCR)}

The first strand cDNA was generated from the RNA samples using iScript RT kits (Bio-Rad). qPGR was performed on the cDNA using gene-specific primer sets that are different from the primer sets for the RNAi DNA construct. It was performed using the SsoFast SYBR ${ }^{\circledR}$ Green supermix (Bio-Rad) with the quantitative analysis and statistical significance empirically calculated by the CFX Manager ${ }^{\mathrm{TM}}$ software (Bio-Rad). For loading controls, 100-bp products of Paraflagellar rod-A (PFR-A) and $\alpha$-tubulin genes were amplified in the same qPCR assay.

\section{Flow Cytometry}

Flow cytometry was performed on propidium iodide (PI)-stained cells to determine the DNA contents of the cells. At each $24 \mathrm{hr}$ interval after RNAi-induction, cells were fixed, stained and processed for fluorescence activated cell sorting scan (FACScan) analysis according to the previously established protocol [24]. The DNA peaks of PI-stained cells were analyzed with the FACScan analytical flow cytometer (BD Biosciences). FL2-A DNA peaks were calculated using CellQuest software (BD Biosciences). Cells were also harvested, washed once with PBS, attached to Poly-LLysine coated cover slips and mounted in vectashield medium with DAPI (Vector Lab) for microscopic examination of nucleus $(\mathrm{N}) /$ kinetoplast $(\mathrm{K})$ configurations. Percentages of cells with different $\mathrm{N} \& \mathrm{~K}$ configurations in each sample were determined by counting at least 200 cells with an epifluorescence microscope.

\section{Epitope Tagging of Endogenous Proteins in Procyclic- form T. brucei}

The 3'-terminal fragment of CDC27, AP1 and AP2 genes were amplified by PCR and cloned into the pC-PTP-NEO plasmid [35]. The three resulting DNA constructs, pC.CDC27.PTP, pC.AP1.PTP and pC.AP2.PTP were linearized with AvaI, BbsI and XhoI, respectively, and transfected into the strain 427 cells by electroporation. Stable clonal transfectants were selected under $40 \mu \mathrm{g} \mathrm{ml}^{-1} \mathrm{G} 418$. For 3HA-epitope tagging of the endogenous mitotic cycB2/cyc6 gene, the C-terminal fragment of the gene (DB accession number: Tb1 1.01.8460) was amplified from the genomic DNA using gene specific primers and cloned into the pC.3HA.Bla plasmid, which is a modified version of the endogenous targeting 
plasmid pC.PTP.NEO [35], and was transfected into either 29-13 procyclic cells or 29-13 cells with a stably maintained AP2 RNAi plasmid. Transfectant selection was carried out under $10 \mathrm{ug} \mathrm{ml}-1$ Blasticidin.

\section{Western Blotting}

Cells were harvested, washed twice in phosphate-buffered saline (PBS), lysed by sonication in SDA-PAGE laemmli sample buffer and cleared by a brief centrifugation. Samples were fractionated on SDS-PAGE and transferred onto PolyVinylidene DiFluoride (PVDF) membrane (Bio-Rad, CA). After blocking in TBST (20 mM Tris-HCl [pH 7.4], $150 \mathrm{mM} \mathrm{NaCl,} \mathrm{0.1 \%} \mathrm{Tween} \mathrm{20)}$ containing 5\% skim milk, the immuno-blot membrane was probed with primary anti-Prot C HPC4 monoclonal antibodies (Roche diagnostics, CA) and stained with the secondary anti-mouse IgGHRP conjugate (Sigma, MO).

\section{Immunoprecipitation}

Cells were harvested, washed once in PBS and the cells extracted in the lysis buffer $(25 \mathrm{mM}$ Tris-Cl, $\mathrm{pH} 7.6,100 \mathrm{mM}$ $\mathrm{NaCl}, 1 \%$ Nonidet P-40, $1 \mathrm{mM}$ dithiothreitol, and protease inhibitor cocktail) for $30 \mathrm{~min}$ on ice. After being cleared by a brief centrifugation, the lysate was incubated with anti-HA mAb (Sigma, MO) at $4^{\circ} \mathrm{C}$ for $60 \mathrm{~min}$ and then with IgG Sepharose beads overnight. The beads were sedimented by a brief centrifugation, washed in PBS, cooked in SDS-PAGE sample buffer and fractionated on SDS-PAGE. The gel was immuno-blotted onto PVDF membranes (Bio-Rad, CA), and the HA tag was probed with anti-HA HRP-conjugated mAb (Sigma, MO).

\section{Results}

\section{Functional Divergence between Yeast and T. brucei APC/ C Subunits}

It has been generally believed that a strong evolutionary conservation of $\mathrm{APC} / \mathrm{C}$ function exists among $\mathrm{APC} / \mathrm{C}$ subunit proteins in organisms as diverse as Drosophila, Caenorhabditis elegans, human and yeast $[44,45,46]$. Although sequence identities among the individual subunit genes are in the range of only 9.6 to $25.5 \%$ and sequence similarities in the range of only 21.5 to $54.5 \%$ (data not shown), Drosophila APC11 [45], G. elegans CDC26 [44] and human APC13 [46] were found capable of complementing their counterparts in yeast. T. brucei APC/C subunits have 13.4 $23.0 \%$ sequence identity and $35.1-42.3 \%$ sequence similarity with the yeast counterparts, which are not significantly different from the other metazoa. In order to clarify if some of the T. brucei APC/C subunits are capable of replacing the essential functions of their yeast counterparts, we performed yeast complementation assays to cover a total of $5 \mathrm{~S}$. cerevisiae temperature sensitive mutants apc1-1, cdc27-1, cdc16-1, cdc23-1 and apc10-1 [29] with the corresponding $\mathrm{T}$. brucei subunit homologues. Results observed at the restrictive temperature showed that the growth of yeast mutant cells was fully rescued by homologous expression of the corresponding yeast genes (Figure 1). But heterologous expression of the corresponding $\mathrm{T}$. brucei genes failed to rescue yeast cell growth in all 5 cases tested (Figure 1). Therefore, none of the five T. brucei APC/C subunit homologues was capable of complementing their counterparts in the yeast. There could be thus a significant structure-function discrepancy between the APG/C's of the two organisms (see Discussion below).

\section{TAP of the APC1-PTP Protein Complex from T. brucei}

In order to identify the intact APG/C core from T. brucei, the potential scaffold protein subunit APG1 in the complex $[29,47]$ was tagged with a PTP and expressed in the procyclic form of T. brucei via homologous genetic recombination. The APC1-PTP fusion protein was then gently isolated from the cell lysate using a well-established TAP procedure for purifying the entire APC/C from T. brucei $[10,35]$.

A stably transfected procyclic-form cell line of $\mathrm{T}$. brucei strain 427 expressing APC1-PTP was isolated and the expression of APC1-PTP in the crude lysate was confirmed with Western blotting (Figures 2A lane 2 and 2B, lane 1). During the TAP, Western blots indicated that the fusion protein was successfully bound to the IgG beads (Figure 2B, lane 2) and eluted after TEV protease digestion in a somewhat reduced molecular mass as anticipated (Figure 2B, lane 3). The cleaved fusion protein was then adsorbed to a column of anti-protein $\mathrm{C}$ beads (Figure 2B, lane 4) and eluted effectively with EGTA (Figure 2B, lane 5) resulting in a final preparation of purified APC/C. Samples from each step of purification were examined with SDS-PAGE stained with SYPRO-Ruby (Figure 2C). The stained gels showed consistent changes of protein profiles through each step of purification with a significant purification of the protein sample achieved after TEV protease digestion and elution from IgG-beads (Figure 2C, lanes $2 \& 3$ ). Further enrichment and elimination of individual proteins were achieved after adsorption to the antiprotein $\mathrm{C}$ beads and elution with EGTA. The protein profile of the final product analyzed with SDS-PAGE (Figure 2C, lane 5) was highly reproducible among several preparations of cells (comparing Figure 2C, lane 5 and Figure 3A).

The protein profile represents the likely APG/C composition from an asynchronous cell population, which is a population enriched with G1 cells up to $80 \%$ shown in flow cytometry (Figure 3A). The cells were then synchronized with $0.3 \mathrm{mM}$ hydroxyurea by an established procedure [37] resulting in $100 \%$ of the cells arrested in late S-phase (Figure 3B). They were then released from hydroxyurea and allowed to grow synchronously for $2.5 \mathrm{hrs}$ when $65 \%$ of the population was found to have reached the metaphase and $15 \%$ in the anaphase in flow cytometry and immunofluorescence assays using chromosome passenger complex 1 (CPC1) protein as the marker (Figure 3C, Figure S1) [10]. When the time period of synchronous growth was extended to $4.5 \mathrm{hrs}$, $65-70 \%$ of the cells were in the anaphase, whereas the rest of the cells had apparently gone beyond cytokinesis and reached the G1 phase (Figure 3D, Figure S1). The method thus enabled us to prepare large batches of procyclic-form $\mathrm{T}$. brucei cells enriched in G1-phase, S-phase, metaphase and anaphase, respectively, and subject them to the TAP (Figure 3). The results from SDS-PAGE of the purified APC1-PTP protein complexes from the cells enriched in different phases of the cell cycle are presented in Figure 3 for direct comparisons. The protein profiles of each sample appear highly similar to one another, and the intensities of individual protein bands stained with SYPRO-Ruby in the gels appear also relatively unchanged among the four cell samples (Figure 3). This preliminary observation provides an indication that $\mathrm{T}$. brucei APC/C remains relatively unchanged throughout the cell cycle without any association or dissociation with other protein $(\mathrm{s})$. This tentative conclusion requires further verification with LC/MS/MS, which is capable of also identifying the individual APC1-PTP-assocaited proteins and compare them with the $7 \mathrm{APC} / \mathrm{C}$ subunit homologues previously found in $\mathrm{T}$. brucei genome database [23].

\section{LC-MS/MS Analyses of T. brucei APC/C Derived from Different Phases of Cell Cycle}

Samples of the APG1-PTP fusion protein complex purified from duplicate or triplicate cell samples, each enriched in different 
$25 \mathrm{C}^{\circ}$

$37 \mathrm{C}^{\circ}$

\begin{tabular}{|llllllllll} 
& Dilution & $1 X$ & $10 X$ & $100 X$ & $1000 X$ & $1 X$ & $10 X$ & $100 X$ & $1000 X$ \\
\hline WT & & & & & & & & & \\
\hline
\end{tabular}
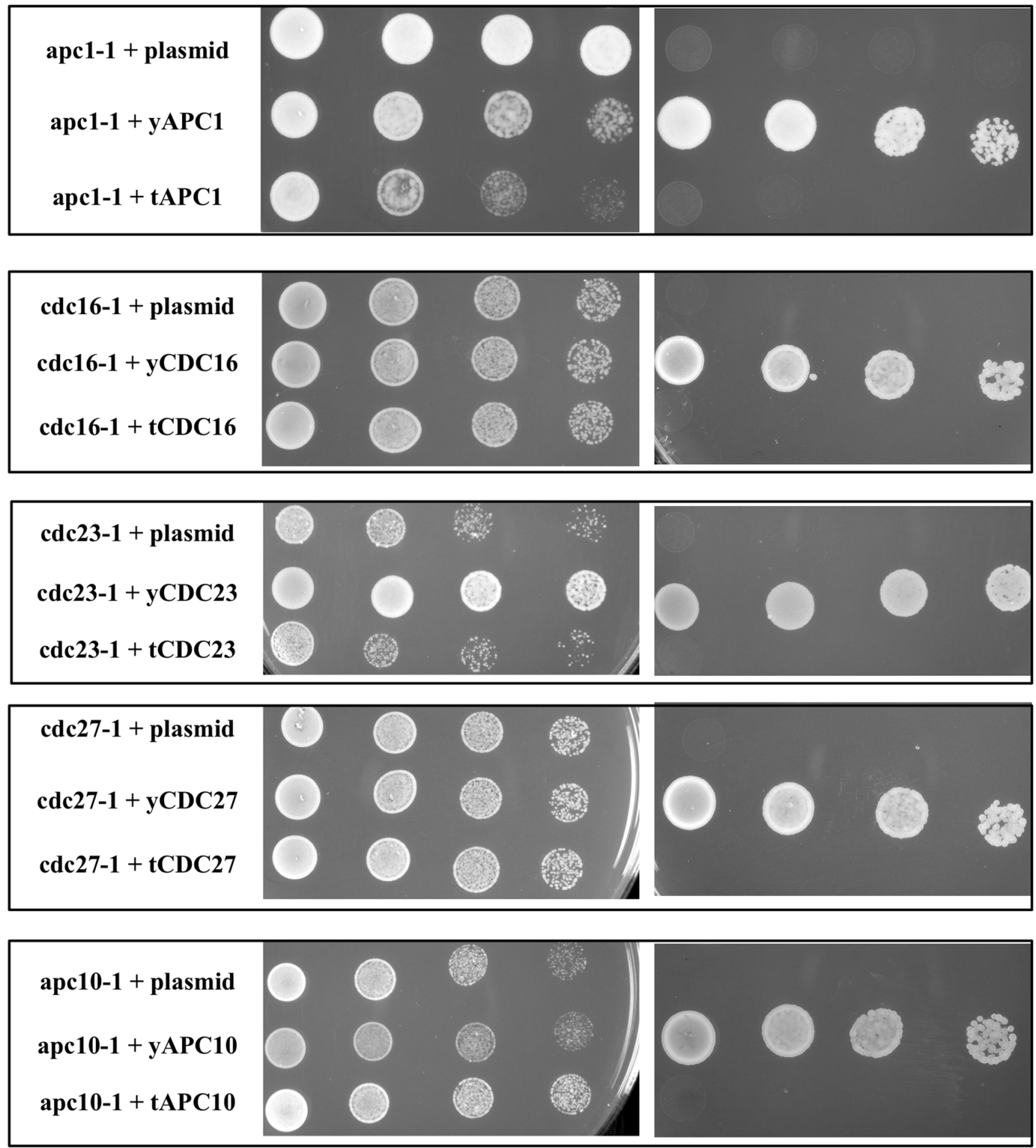

Figure 1. Functional divergence between $T$. brucei and yeast APC/C subunits. Yeast complementation assay. Temperature-sensitive ( $t s$ ) yeast mutants of APC/C subunit genes apc1-1, cdc16-1, cdc23-1, cdc27-1 and apc10-1 were transformed with pRS416-ADH plasmids expressing corresponding yeast $(\mathrm{y})$ or $T$. brucei $(\mathrm{t})$ full-length APC/C genes. After transformation and selection, the cloned cells were grown either at the permissive $\left(25^{\circ} \mathrm{C}\right)$ or the restrictive $\left(37^{\circ} \mathrm{C}\right)$ temperature. Wild-type W303 (WT) cells and yeast ts mutant cells transfected with the empty vector (plasmid) were used as positive and negative controls, respectively. doi:10.1371/journal.pone.0059258.g001 
A

B

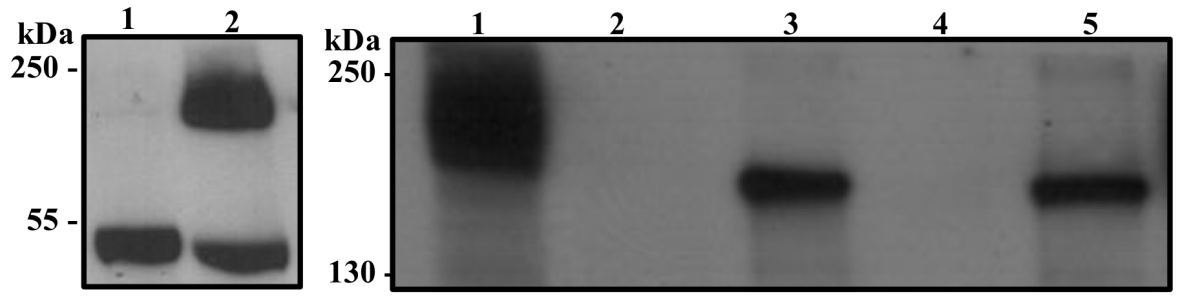

C

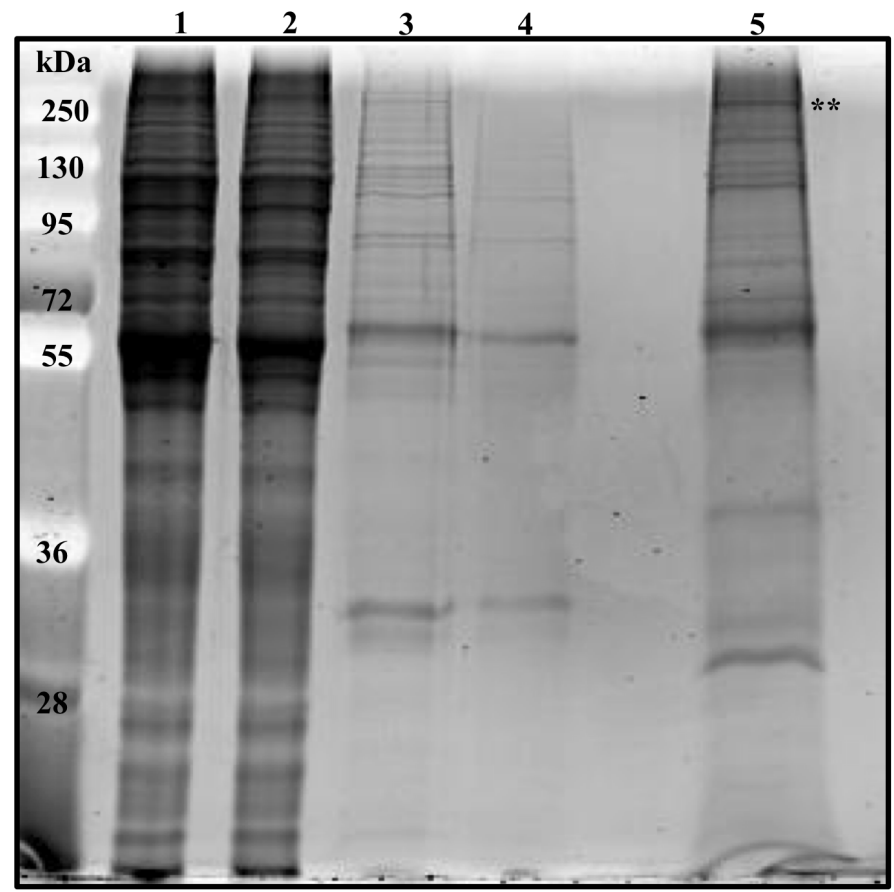

Figure 2. TAP of APC1-PTP and identification of APC1-associated proteins. (A) Lysates of strain 427 cells transfected either with empty vector (control, lane 1) or PC.APC1.PTP (lane 2) were fractionated on 10\% SDS-PAGE gel, Western blotted and simultaneously probed with antiprotein C antibody (HPC4) and anti-tubulin. The blot was then detected with an anti-mouse HRP-conjugated secondary antibody. (B) Stepwise Western blot monitoring of APC1-PTP during TAP. Samples were analyzed from 1. IgG input (1x), 2. IgG-Sepharose flow-through (1x), 3. The elute from lgG-Sepharose after TEV-protease digestion (5x), 4. The flow-through from anti-protein C matrix (5x), and 5. The EGTA final elute (20x). The blot was probed with HPC4 antibody and the values (in x) represent the relative amounts of samples analyzed. (C) Samples collected from TAP as in (B) were fractioned on $10 \%$ SDS-PAGE gel and stained with SYPRO-Ruby. $\left.{ }^{* *}\right)$ on the top indicates the position of APC1-PTP fusion protein. doi:10.1371/journal.pone.0059258.g002

phases of the cell cycle, were fractionated in SDS-PAGE (Figure 3). Individual protein bands in the gels were sliced out, diced and digested with trypsin by the well-established procedures. As a control, lysate of 427 cells transfected with empty pC.PTP plasmid was purified by the same procedure and individual protein bands were sliced from the SDS-PAGE and processed for trypsin digest as mentioned above. Each digest was then fractionated with LC, and subjected to MS/MS analysis for peptide identification. The results in protein identities versus the individual protein bands in a SDS-PAGE gel, are represented in Figure 3A of a sample purified from a cell population enriched in Gl phase. Thirteen proteins are identified in the purified APG-PTP complex. Other than the persistent presence of $\alpha$-tubulin, $\beta$-tubulin and TEV protease, which are also present in the control sample and are thus likely common contaminants (data not shown), the rest of the 10 proteins in the purified complex are found to include the $7 \mathrm{APC} /$ $\mathrm{C}$ subunit proteins originally derived from $\mathrm{T}$. brucei genome database plus 3 un-identified proteins designated the APG/C-
Associated Proteins (AP); AP1, AP2 and AP3, respectively. The rest of the undefined protein bands have also been analyzed, and they were primarily degradation products from the 10 identified proteins and the high abundance background proteins.

These 10 identified proteins all appeared in the purified APC/C samples from the G1-phase (Figure 3A), S-phase (Figure 3B), metaphase (Figure 3C) and anaphase enriched cells (Figure 3D) at relatively unchanged quantities. There has been no other protein detected in any of the 4 purified APC/C samples, which suggests that there is no additional protein above the limit of detection that is associated with APC/C that could sustain the mild TAP experimental conditions during any phase of the cell cycle progression of $\mathrm{T}$. brucei. The 10 proteins may thus constitute the core subunits of the $\mathrm{APC} / \mathrm{C}$ in $\mathrm{T}$. brucei.

More detailed data from the MS/MS analysis are presented in Table 1 and Table S1. The estimated molecular masses of the 7 APC/C subunits all agree well with those derived from the genomic database. All the proteins are each identified with 
A
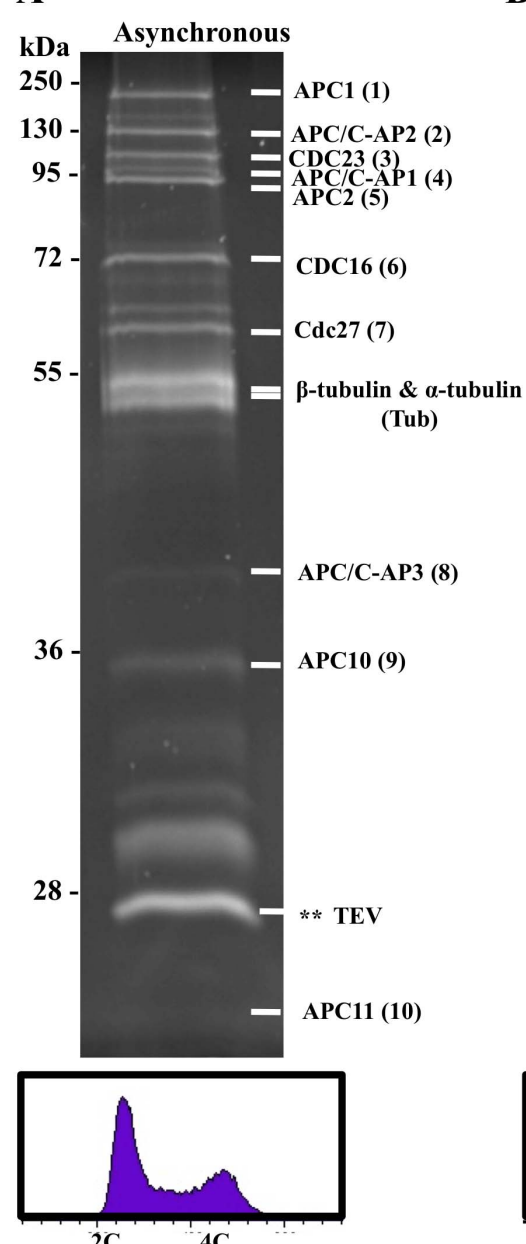

B
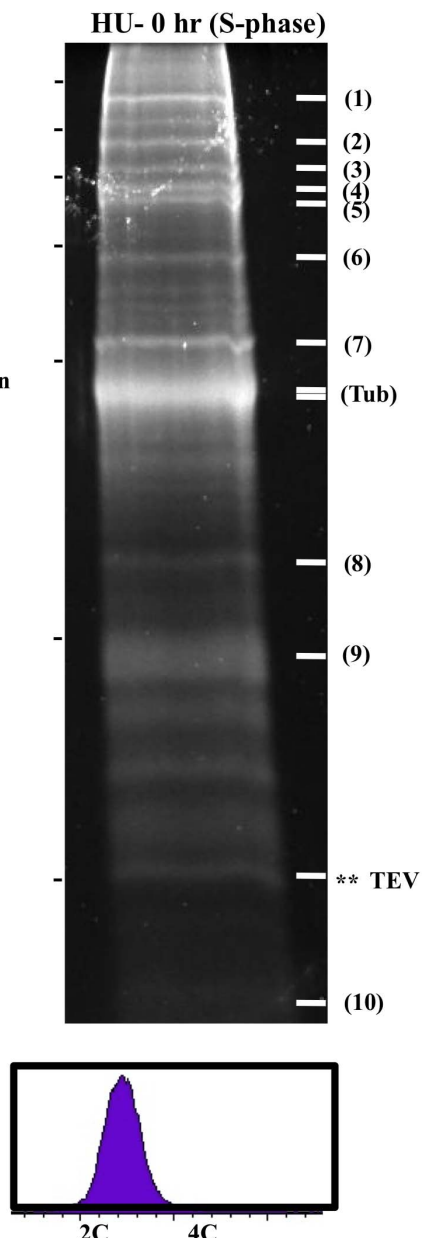

C

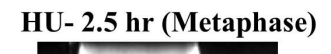

HU- 2.5 hr (Metaphase)

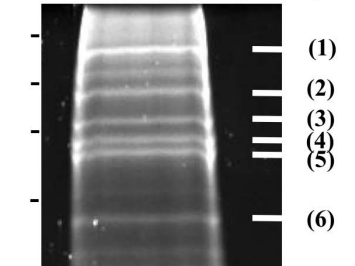

(6)

(7)

(Tub)

(8)
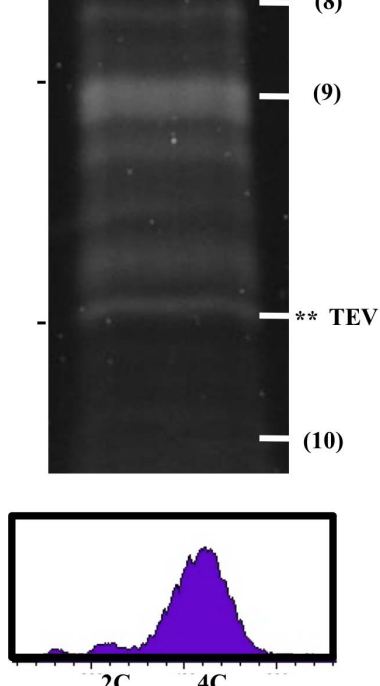

D
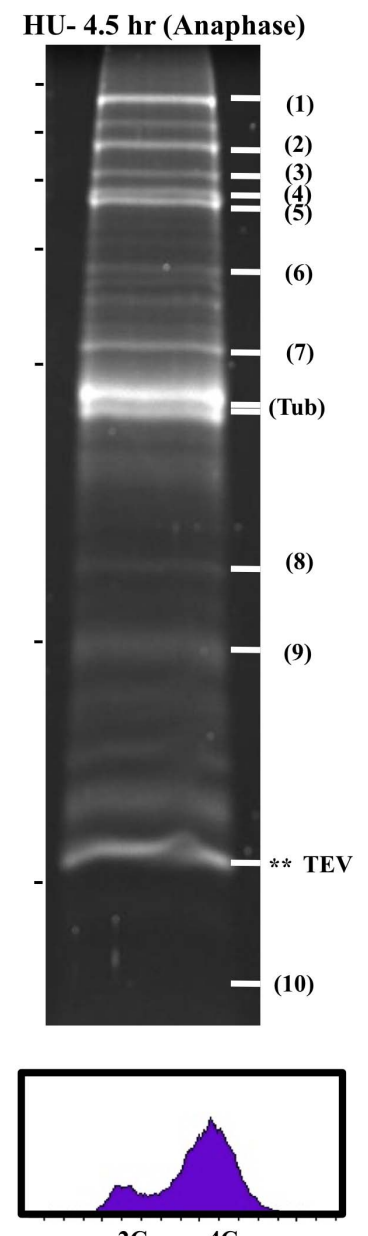

Figure 3. The $T$. brucei APC/C profiles during different phases of the cell cycle progression. The final EGTA elutes from TAP of APC1-PTP from $(\mathbf{A})$ the G1 phase enriched cells; (B) The late S-phase cells; (C) The metaphase enriched cells and (D) The anaphase enriched cells were each fractioned in $10 \%$ SDS-PAGE and stained with SYPRO-Ruby. The individual protein bands identified by subsequent LC-MS/MS analysis are indicated on the right-hand side of each gel panel with the molecular masses (in $\mathrm{kDa}$ ) indicated on the left-hand side. Tub and TEV denote contaminating tubulins and TEV protease, respectively. The cell samples were also analyzed by flow cytometry and the histograms of cellular DNA contents are displayed below the corresponding SDS-PAGE panels. doi:10.1371/journal.pone.0059258.g003

adequate numbers of unique peptides and sufficient percentages of coverage in the two tables with but one exception with APC11; data on this protein are apparently missing in the samples from G1-phase and anaphase enriched cells. This is most likely attributed to the relatively low molecular weight of APC11 $(10 \mathrm{kD})$ that facilitates diffusion of the protein from the gel during SDS-PAGE $[48,49]$. This small protein is thus still considered an integral component of $\mathrm{T}$. brucei APC/C.

To further verify that there is no significant fluctuation of the intracellular levels of $\mathrm{APC} / \mathrm{C}$ subunits during cell cycle progression, APC1, CDC27, AP1 and AP2 were each tagged with PTP at the C-termini, integrated into chromosomes via homologous recombination and expressed in transfected cells as previously described. The transfected cells were then synchronized with hydroxyurea into late S-phase [37] and released for synchronized growth for $8 \mathrm{hrs}$, which covers the entire cell cycle of T. brucei [3]. Hourly samples were taken during the incubation and examined on Western blots. The results, presented in Figure $\mathrm{S} 2$, indicated little changes of the protein levels in the four samples, suggesting limited fluctuation in the level of APC/C subunits during cell cycle progression of procyclic-form $\mathrm{T}$. brucei.

\section{Tentative Identification of AP1 as APC4}

In NCBI BLAST analysis, the sequence of AP1 was successfully aligned with the protein fragments from the core $\mathrm{APC} / \mathrm{C}$ subunit APC4 from several eukaryotic organisms including Schizosaccharomyces pombe and Arabidopsis thaliana (data not shown). By searching the domain database of Pfam for specific motifs, the most significant structural similarity between AP1 and the APC4's was identified in the Apc4-WD40-like domain. The Pfam-A (CL0186) domain database identified a bit score of 11.2 and an $\mathrm{E}$ value of 0.18 for AP1. The WD40 domain in APC4 is an N-terminal propeller-shaped domain that serves to stabilize the interaction with APC5 in the APG/C complex [50]. All known APC4 proteins have been found to contain a single N-terminal WD40-like domain except for the $A$. thaliana and T. brucei homologues, each of which contains two WD-40-like domains (data not shown). This finding was further confirmed by a reciprocal BLAST analysis 


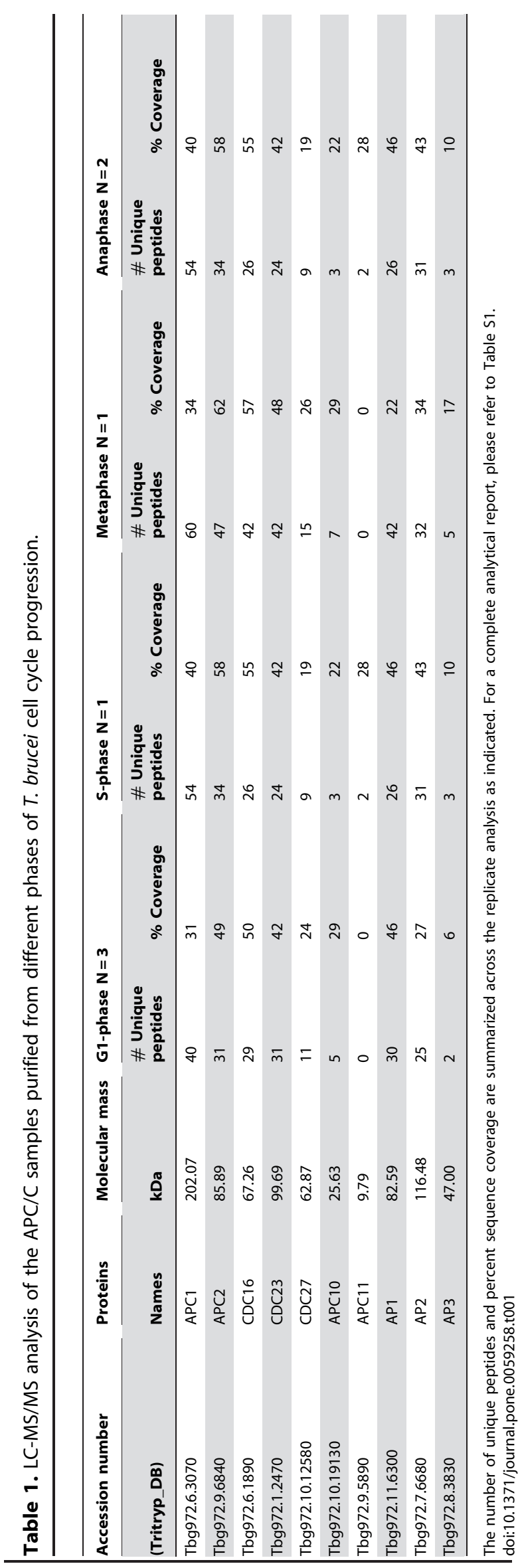

searching the TriTryp database with yeast and vertebrate APC4 sequences. APl is thus re-designated APC4.

AP2 and AP3 remain unidentified after extensive BLAST and domain search analysis. But their orthologues have been found in the genomic databases of Trypanosoma cruzi and Leishmania major (data not shown), suggesting that they could be the common core subunits of $\mathrm{APC} / \mathrm{C}$ among all Kinetoplastidae.

\section{RNAi Knockdown of AP2 Arrested the Cells in G2/M Phase}

Expression of the three newly identified APC/C subunits was each knocked down with RNAi for potential cell phenotype. By inducing target-specific RNAi in procyclic-form cells [33], specific mRNAs were significantly depleted. Data from qPCR showed that APC4 mRNA was almost totally depleted (Figure S3A), AP2 transcript was reduced more than $80 \%$ (Figure 4A), whereas AP3 mRNA was also knocked down by $80 \%$ (Figure S4A). Only the knockdown of AP2, however, turned out to demonstrate a clear phenotype; the cells continued to grow for two more days following the RNAi induction, but apparently ceased growing thereafter (Figure 4B). Microscopic examination of DAPI-stained cells showed a gradual increase of cells containing 1 nucleus and 2 kinetoplasts $(1 \mathrm{~N} 2 \mathrm{~K})$ and a slow reduction in the number of $2 \mathrm{~N} 2 \mathrm{~K}$ cells when compared with the control (Figure 4G). The elongated nucleus and two well segregated kinetoplasts in the $1 \mathrm{~N} 2 \mathrm{~K}$ cells suggest that the cells are arrested in metaphase $[3,51,52]$ (Figure 4C, left lower panel). There was also a dramatic increase of $0 \mathrm{~N} 1 \mathrm{~K}$ cells (zoids) (Figure 4C, right lower panel) up to $25-30 \%$ of the total cell population on day 4 of the RNAi induction. This is a hallmark of the procyclic cells arrested during mitosis, in which cytokinesis and cell division still carries on, generating anucleated cells $[4,6]$. All these data thus provide a strong indication that the procyclic-form cells are arrested during mitosis, likely in the metaphase, following a knockdown of AP2. Flow cytometry indicated a diminished $2 \mathrm{C}$ cell numbers and an increase of $4 \mathrm{C}$ cell population plus a prominent band of cells with less than a $2 \mathrm{C}$ DNA content after 4 days of RNAi, most likely the zoids (Figure 4D). Thus all the experimental data point to a blocked mitosis, which are highly similar to the data from a knocking down of APC1 or CDC27 in our previous study, showing that the procyclic-form $\mathrm{T}$. brucei was arrested in the metaphase [23]. Being a likely subunit of $\mathrm{APC} / \mathrm{C}$, the knockdown of AP2 may also result in a blocking of metaphase-anaphase transition.

APC4 and AP3 were also knocked down, but the results, presented in Figures S3 and S4, indicated no clear phenotype. They are thus classified as the APC/C subunits like APC2, CDC16, CDC23, APC10 and APC11; whose knockdowns from T. brucei did not register a phenotype [23].

\section{AP2 Depletion Stabilized the Mitotic Cyclin CycB2/cyc6}

Following our tentative identification of the composition of $\mathrm{APC} / \mathrm{C}$ in $\mathrm{T}$. brucei, the next question concerned the potential function of this protein complex. Since a homologue of securin/ Pds1 has not yet been found in T. brucei, we focused our attention on another commonly known substrate of $\mathrm{APC} / \mathrm{C}$; the mitotic cyclin $\mathrm{B}$, whose destruction by the combined actions of APC/C and $26 \mathrm{~S}$ proteasome toward the late phase of mitosis is required for mitotic exit in yeast and metazoa [22,53]. A functional homologue of mitotic cyclin B, cycB2/cyc6, has been identified in $\mathrm{T}$. brucei $[4,28]$. It is involved in activating the mitotic CDK cdc2related-kinase 3 (CRK3) during mitosis [4]. An RNAi knockdown of cycB2/cyc6 arrested T. brucei in the G2/M phase [28], though a potential disappearance of $\mathrm{cycB} 2 /$ cyc6 from $\mathrm{T}$. brucei in the late phase of mitosis has not yet been studied. 
A

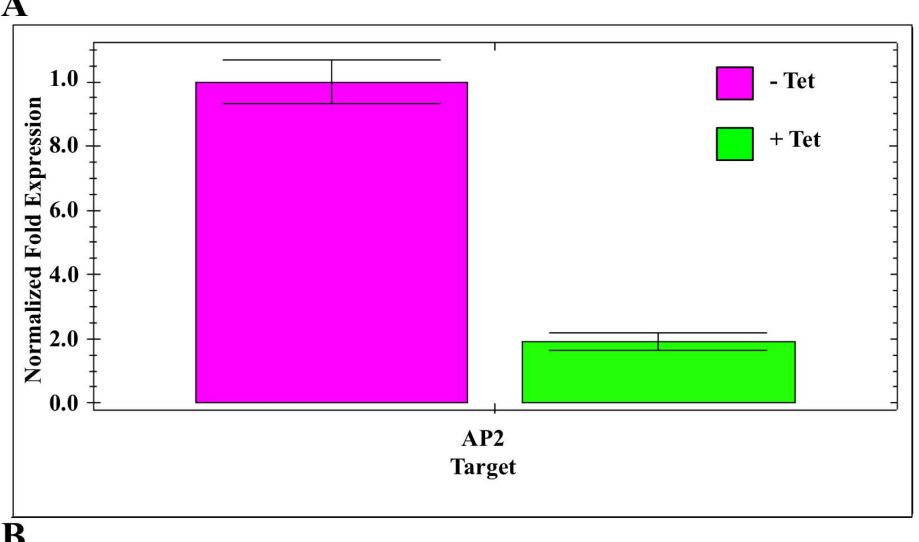

B

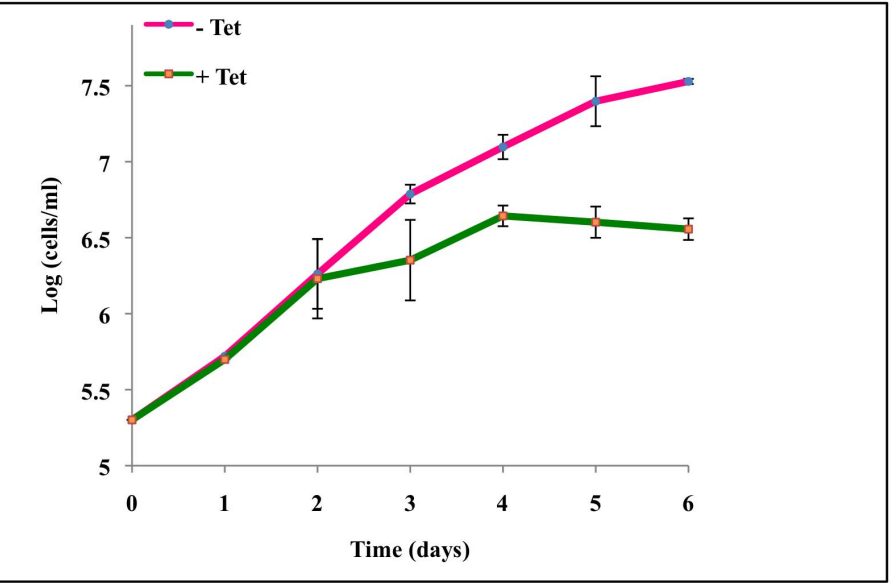

C



D

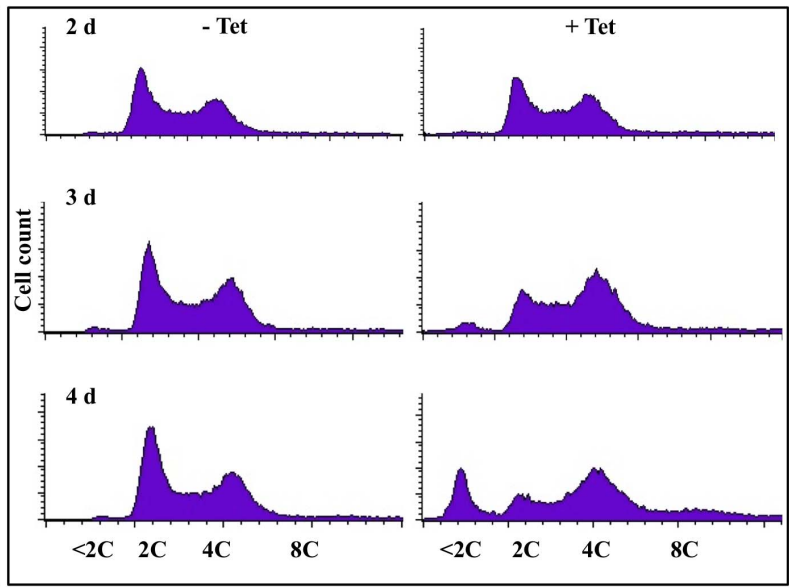

Figure 4. RNAi knockdown of AP2 in T. brucei procyclic cells. (A) Specific AP2 mRNA depletion was assayed with qPCR after RNAi induction for 72 hours. Data are derived from two independent experiments with standard deviation ( \pm SD) error bars displayed. (B) The rate of cell growth after RNAi induction. The mean \pm SD values are derived from two independent experiments. (C) Time samples (d, days) of the RNAi-induced cells were stained with DAPI and analyzed with a microscope for numbers and configurations of nucleus (N)/kinetoplast (K) among individual cells. Data are presented as percentages of cells from a total number of $\sim 200$ cells at each time point from two independent induction experiments. Error bars represent the standard deviation (SD) are presented. Representative DAPI-stained 1N2K and 0N1K cells after 4 days of RNAi induction are shown (lower panel). (D) Time-dependent (d, days) changes of DNA profiles in the RNAi-induced cells were analyzed by flow cytometry.

doi:10.1371/journal.pone.0059258.g004

Since an APC2 knockdown in mice and an APG16 depletion in human cells were reported to stabilize the mitotic cyclin B $[48,54]$, we knocked down the expression of AP2, and monitored the fate of $\mathrm{CycB} 2 /$ cyc6 thereafter. To do this, one of the two endogenous alleles encoding $\mathrm{CycB} 2 / \mathrm{cyc} 6$ was tagged with 3HA through homologous recombination and the expression of CycB2/cyc63HA was verified on Western blot (Figure 5A).

The cells expressing $\mathrm{CycB} 2 / \mathrm{cyc} 6-3 \mathrm{HA}$ were treated with $0.3 \mathrm{mM}$ hydroxyurea for $16 \mathrm{hrs}$ for synchronization of the cells in late S-phase, and were released for synchronous growth. Hourly cell samples were taken for Western blot analysis. The results (Figure 5B) showed that following an initial increase in the beginning $3 \mathrm{hrs}$, when the cells entered from the late S-phase into the metaphase (see Figure 3 and Figures S1 \& S5), there was a steady decrease in the level of $\mathrm{CycB} 2 /$ cyc6 thereafter. The decrease continued up to $8 \mathrm{hrs}$ when a full cell cycle was completed [3]. GycB2/cyc6 is thus confirmed to disappear like the other mitotic cyclins in the late phase of mitosis.

To verify if the APG/C in T brucei is involved in regulating the turnover of $\mathrm{CycB} 2 / \mathrm{cyc} 6$, the same experiment was repeated using the AP2 RNAi cell line. In the control cells without RNAi induction, the time course of $\mathrm{CycB} 2 /$ cyc6-3HA level change in the synchronized cells paralleled that observed in Figure 5B except that the heightened level of the cyclin was extended a little longer to 4 hours before the decline (Figure 5C), which could be attributed to slightly different physiological conditions between different batches of synchronized cells. When AP2 RNAi was induced for $48 \mathrm{hrs}$ (see Figure 4B) and the cells were then subjected to hydroxyurea synchronization and released for synchronous growth, expression of AP2 was knocked down as anticipated throughout the synchronization experiment (Figure 5C). The level of $\mathrm{CycB} 2 /$ cyc6 reached the high plateau within 3 to $4 \mathrm{hrs}$, reduced by about $30 \%$ after 5 to $6 \mathrm{hrs}$, but restored to the original high level after 7 to 8 hours (Figure $5 \mathrm{C}$ ). Comparing with the no RNAi induction control, it is clear that a knockdown of AP2 expression resulted in stabilization of $\mathrm{CycB} 2 /$ cyc6 in the late mitotic phase of $\mathrm{T}$. brucei. The progression of synchronized AP2 knockdown cells was also analyzed with flow cytometry and the data are presented in the lower right panel of Figure 5C. When these data are compared with those from the progression of synchronized wild-type cells in Figure S5, it is clear that the progression of AP2 knockdown cells is arrested in the G2/ $\mathrm{M}$ phase. Since AP2 is a core subunit of APC/C, it is most likely that the function of $\mathrm{APC} / \mathrm{C}$ is required for the destruction of CycB2/cyc6 and passage of cells beyond mitosis. From the knowledge derived from other eukaryotes, it is reasonable to 

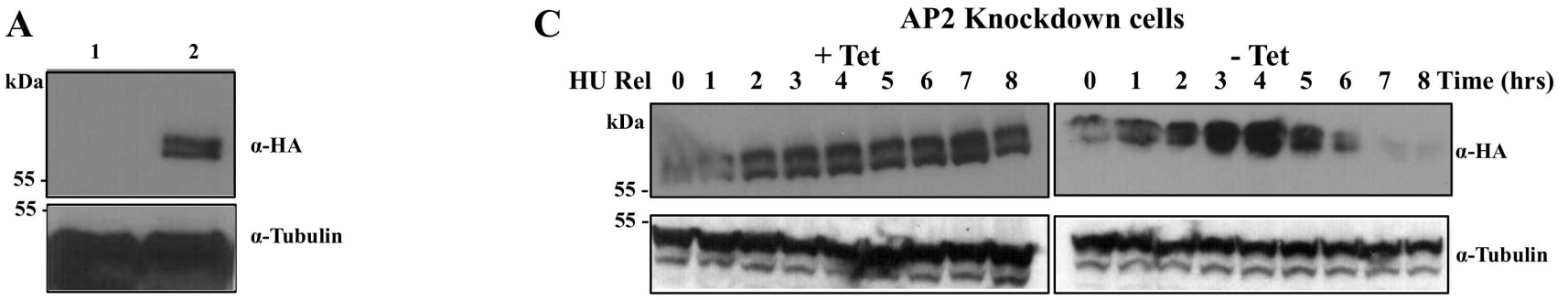

B

Control cells
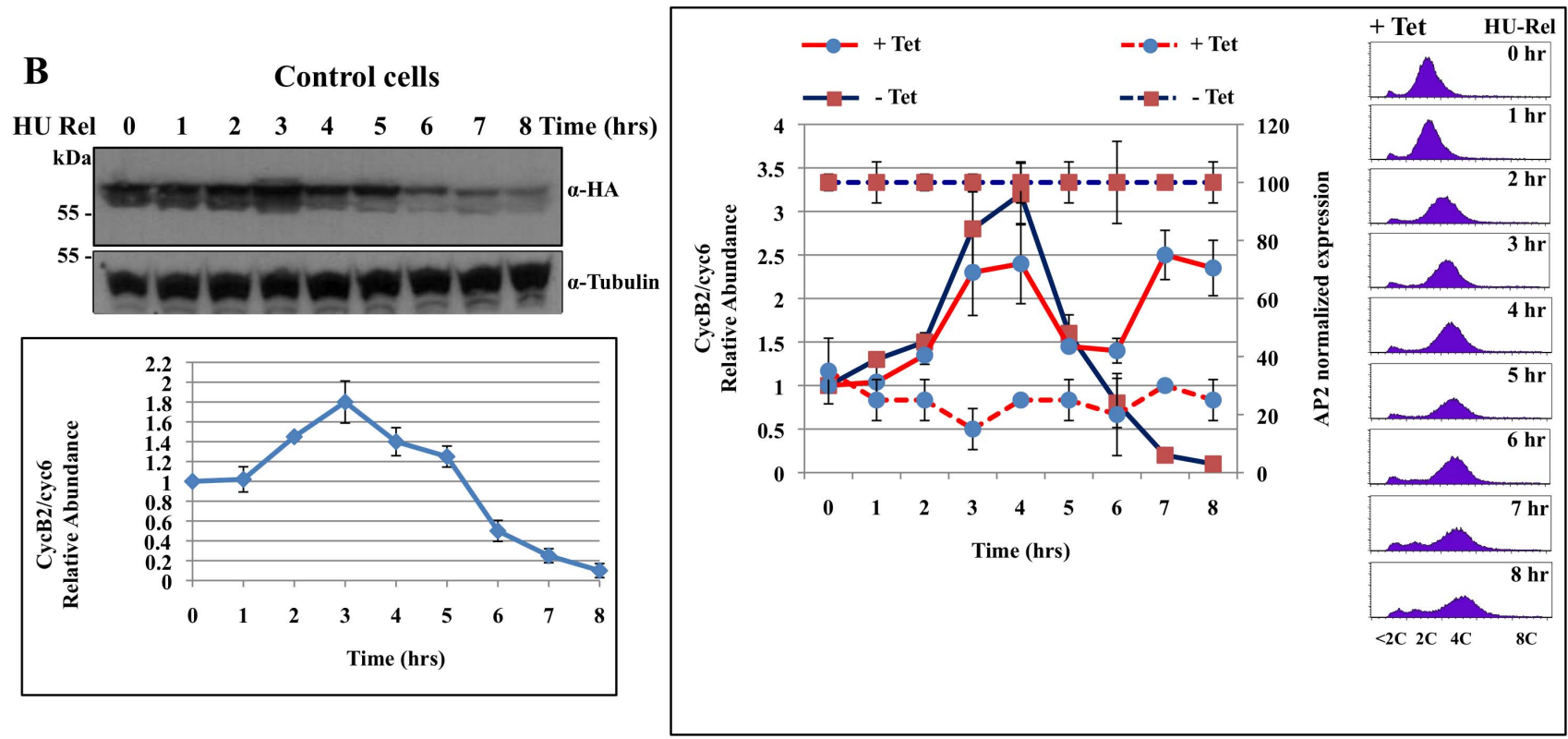

Figure 5. Effect of AP2 knockdown on the expression of CycB2/cyc6 in T. brucei. (A) Western blot analysis of the cell lysates of; 1. wild-type cells; and 2. the cells expressing CycB2/cyc6-3HA. The blot is stained with anti-HA mAb and the anti-tubulin antibody was used as a loading control. (B) The Control Cells; Cells expressing CycB2/cyc6-3HA were synchronized in late S-phase with hydroxyurea and released for synchronous growth for $8 \mathrm{hrs}$ to complete a cell cycle. Hourly cell samples were lysed and fractionated in SDS-PAGE, immuno-blotted and probed with anti-HA mAB for CycB2/cyc6-3HA expression. The time course of level changes of CycB2/cyc6-3HA was quantified against tubulin control using the ImageJ software and presented in the lower panel. The relative abundance of $C y c B 2 / c y c 6$ has a value set at 1 from the zero time point. Error bars represent the SD from two independent experiments. (C) AP2 RNAi cells expressing CycB2/cyc6-3HA were induced (+Tet) for RNAi for 48 hours, and then synchronized to late S-phase with hydroxyurea and released for synchronous growth for 8 hours while the RNAi was maintained. CycB2/cyc6-3HA expression was monitored as described in (B). RT-PCR analysis of AP2 transcript levels in the hourly cell samples was performed. They and the levels of CycB2/cyc6 from the Western analysis are plotted versus time and presented in the lower left panel. Error bars represent the SD from two independent experiments. The same time samples from AP2 RNAi induced culture (+ Tet) after hydroxyurea release were analyzed by flow cytometry and the data are presented in the lower right panel. doi:10.1371/journal.pone.0059258.g005

postulate that the $\mathrm{APC} / \mathrm{C}$ of $\mathrm{T}$. brucei functions as an E3 ligase that poly-ubiquitinates $\mathrm{CycB} 2 / \mathrm{cyc} 6$ and subjects it to $26 \mathrm{~S}$ proteasome degradation.

The Mitotic Cyclin in T. brucei is Likely Poly-ubiquitinated by APC/C and Degraded by 265 Proteasome during Mitosis

The presence of $26 \mathrm{~S}$ proteasome and the structure and function of this protein complex in $\mathrm{T}$. brucei have been thoroughly investigated and identified by us in our previous studies [34,55]. In order to verify if the turnover of $\mathrm{CycB} 2 / \mathrm{cyc} 6$ depends on the function of proteasome in $\mathrm{T}$. brucei, the latter was treated with a reversible inhibitor of proteasome, MG132, at $20 \mu \mathrm{M}$ known to totally inhibit the proteasome activity in T. brucei [56]. Cells expressing CycB2/cyc6-3HA and synchronized with hydroxyurea were released for synchronous cell cycle progression in the presence of MG132. Hourly cell samples were taken for immunoprecipitation with anti-HA followed by analysis on Western blot stained with the antibodies to HA or ubiquitin.
The results showed that while there is a drop of CycB2/cyc6 level in the cells after $3 \mathrm{hrs}$ without MG132 treatment as anticipated (Figure 6A, upper panel), it keeps increasing up to 6-fold of the original value after $8 \mathrm{hrs}$ of growth in the presence of MG132 (Figure 6B, upper panel). Apparently, the proteasome function is required for the degradation of $\mathrm{CycB} 2 /$ cyc6 during mitosis of $T$. brucei. The time-dependent accumulation of ladders of higher molecular mass bands in the MG132 treated samples suggests also formation of poly-ubiquitinated CycB2/cyc6 (Figure 6B, upper panel).

When the Western blot of the anti-HA immunoprecipitate was stained with anti-ubiquitin, there was little specific staining for poly-ubiquitinated proteins while MG132 was not present (Figure 6A, middle panel). In the presence of MG132, however, there was a steady increase in the intensity of a ladder of protein bands on top of the $\mathrm{CycB} 2 /$ cyc6 band beyond the mitotic phase of the cells (Figure $6 \mathrm{~B}$, middle panel). They are most likely the polyubiquitinated $\mathrm{CycB} 2 /$ cyc6 that cannot be degraded when the 
A



$\begin{array}{lllllllllll}\text { HU Rel } & 0 & 1 & 2 & 3 & 4 & 5 & 6 & 7 & 8 & \text { Time (hrs) }\end{array}$
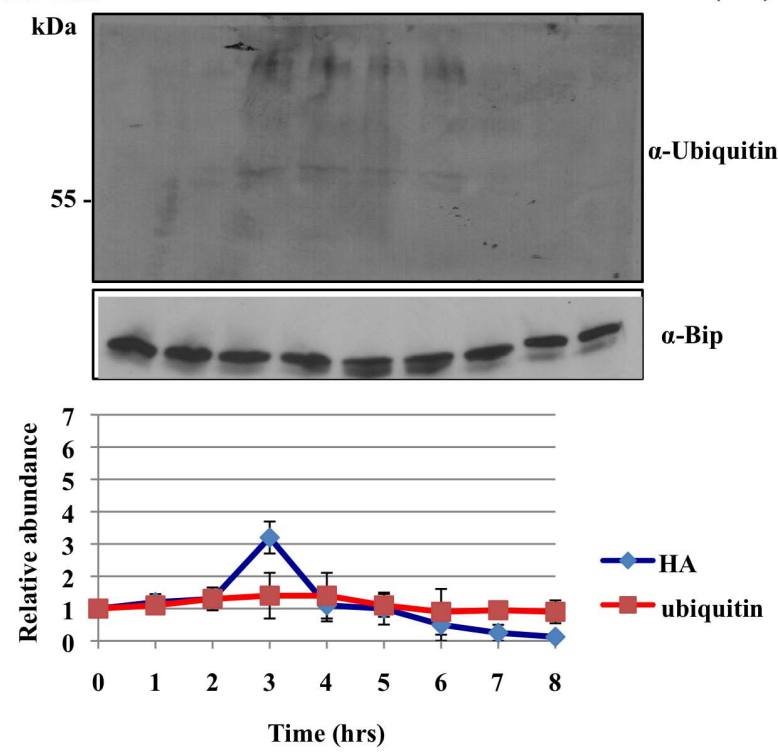

B + MG132
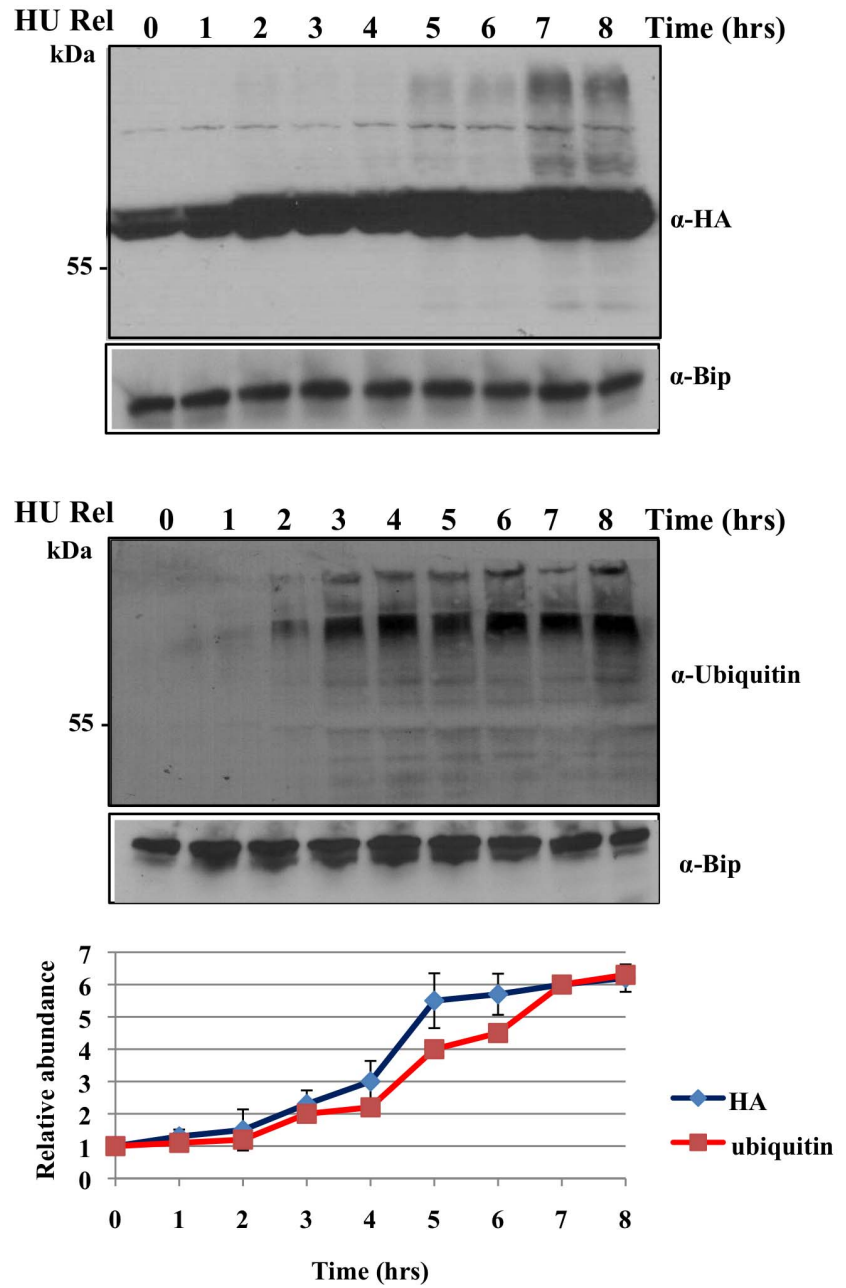

Figure 6. Polyubiquitination and proteasome degradation are involved in the turnover of CycB2/cyc6 during mitosis. Cells arrested in late S-phase by hydroxyurea treatment were released for synchronous growth for 8 hours in the absence (A) or the presence (B) of $20 \mu \mathrm{M}$ MG132. Hourly cell samples were lysed, subjected to immunoprecipitation with anti-HA mAb and fractionated with SDS-PAGE. Western blotting was used to analyze the time course of the level of CycB2/cyc6-3HA with anti-HA mAb (upper panels) or polyubiquitination staining with anti-Ubiquitin (Sigma, U5379) antibody (middle panels). Anti-Bip was used as loading controls. A quantitative analysis of CycB2/cyc6-3HA relative abundance and ubiquitin staining intensity for each experiment were plotted versus time in the bottom panels. Error bars represent the SD from two independent experiments.

doi:10.1371/journal.pone.0059258.g006

proteasome activity is inhibited. It is probable that the polyubiquitinated $\mathrm{CycB} 2 / \mathrm{cyc} 6$ is a product of the APC/C action.

\section{Discussion}

In the present study, we indicated that among the five APG/C subunit homologues in T. brucei; APC1, CDC16, CDC23, CDC27 and APC10, none was capable of complementing the function of their counterparts in yeast. Although APC/C has a conserved presence and function among all the eukaryotes examined thus far, the sequences of individual APG/C subunit proteins do not appear to be highly conserved [12]. Drosophila APC11 [45], C. elegans CDC26 [44] and human APC13 [46] have been, however, tested in the yeast complementation assays and found capable of substituting the corresponding subunits in yeast. It makes thus the negative outcome from testing all $5 \mathrm{~T}$. brucei subunits a little difficult to explain from a simple view on protein sequence discrepancies. An alternative explanation could be by postulating a distinctive mechanism of inter-subunit interactions in constituting the $\mathrm{APC} / \mathrm{C}$ in $\mathrm{T}$. brucei, i.e., $\mathrm{T}$. brucei $\mathrm{APC} / \mathrm{C}$ subunits may be incapable of incorporating into yeast $\mathrm{APC} / \mathrm{C}$.

The assembly and three-dimensional structure of APC/C remain poorly understood for the time being [57]. Threedimensional electron microscopic structural analysis of yeast APC/C located APC1 in an L-shaped rod that links APC2 to CDC23, whereas CDC23 is connected to APC5 with APC4 interconnecting APC1 and APC5 [58,59]. APC1, the largest APG/C subunit, consists of 11 highly repetitive 35-40 amino acid proteasome-cyclosome $(\mathrm{PC})$ sequences at the $\mathrm{C}$-terminus. This $\mathrm{PC}$ motif is shared with the RPN1 and RPN2 subunits of the proteasome $19 \mathrm{~S}$ regulatory particle [60], and is assumed to be the main binding sites for other subunits in forming APC/C. APC/C purified from the yeast mutant apc1A was found lacking association among the majority of other subunits [29]. APC1 is 
thus classified as the major scaffold protein in yeast APC/C [29]. These 11 PC repeats are, however, absent from T. brucei APC1 (data not shown), which could provide a supporting evidence that T. brucei APG/C may have a mechanism of assembly highly distinctive from that in yeast. This distinction may explain why the APC/C subunits from $\mathrm{T}$. brucei are not complementary to the corresponding subunits missing from the yeast.

The outcome from our TAP and LC-MS/MS analysis of APC1-PTP protein complex indicates that T. brucei APC/C is made of 10 core subunit proteins. The composition and level of APG/C remain apparently unchanged throughout the entire cell cycle of procyclic-form T. brucei. An even more intriguing finding was that neither CDC20 nor MCC complex proteins were found associated with APC/C during any phase of the cell cycle. This is in contrast to that observed among the other eukaryotes. An intact MCG complex with GDC20 protein had been co-purified with APC/C subunits using a similar TAP procedure in human cells [48]. Also, CDC20 was detected in the mitotic-enriched APG/CTAP sample from the budding yeast and fission yeast [47]. In budding yeast, the MCC components MAD1, MAD2 and MAD3 were co-immunoprecipitated with epitope-tagged CDC20 throughout different stages of the cell cycle [61]. A common factor enabling all the complex formations mentioned above is CDC20. The fact that the T. brucei CDC20 homologue is not associated with APC/C at all during all phases of the cell cycle shows that it is not performing the function of mediating a binding of $\mathrm{APC} / \mathrm{C}$ to $\mathrm{MCC}$ or activating $\mathrm{APC} / \mathrm{C}$ to poly-ubiquitinate mitotic cyclin $\mathrm{CycB} 2 / \mathrm{cyc} 6$ [62]. Our previous finding that an RNAi knockdown of CDC20 showed no detectable cell phenotype (data unpublished) tends to support this conclusion. The CDC20 homologue in $\mathrm{T}$. brucei could be a structural homologue but not a functional one.

Our findings that there is no apparent structural homologues of MCG subunits in T. brucei genomic database (data not shown) and that no detectable protein was found associated with APC/C in the metaphase and dissociated from it in the anaphase of $\mathrm{T}$. brucei provide a strong indication that this organism may not have a similar mechanism of regulating metaphase-anaphase transition as observed in other eukaryotes $[63,64]$. A similar observation has been also made in the budding yeast, in which neither the MCG subunit protein MAD2 nor the spindle assembly checkpoint complex is required for normal cell growth $[65,66]$. This peculiarity was attributed to the persistent presence of mitotic spindles throughout the yeast cell cycle [65]. It may not require specific spindle assembly prior to mitosis to facilitate capture of the mitotic microtubules by the kinetochores in chromosomes and biorientations of the chromosomes on the mitotic spindle [65]. T. brucei is an even more primitive organism than yeast and may not maintain an active regulation of spindle assembly either. This postulation may explain the apparent absence of a MCG-like complex in T. brucei. But the mechanism of activation of APC/C in triggering the metaphase to anaphase transition remains still unclear. The question whether a functional homologue of securin/ Pdsl is present in T. brucei requires still an answer.

Other than the 7 subunits already identified in T. brucei APG/ C genome DB [23], three additional subunit proteins, APC4, AP2 and AP3, were identified in this protein complex. AP2 and AP3 cannot find homologous proteins in all the genomic databases other than those of Kinetoplastidae. Searches for common motifs in APG/C subunits such as PC repeats, cullin homology, TPR, RING H2 and WD40/IR in these two proteins also turned out negative results. AP2 and AP3 could thus be specific subunits of only the APC/C's among the Kinetoplastidae.
Among the 10 core subunits identified in T. brucei APG/C, only a knockdown of three of them, APC1 [23], CDC27 [23] and AP2, each resulted in an arrest of T. brucei procyclic-form cells in the metaphase. In budding yeast, 8 of the 13 APG/C subunits (APC1, APC2, APC4, APG5, APG11, CDG16, GDC23, CDC27) were found indispensible for viability. Their depletion abrogates the APC/C catalytic activity and blocks yeast cell cycle progression $[25,50,67,68]$. The rest of the subunits are either nonessential (APC9, CDC26, SWM1, MND2) [25,46], or their loss (APC10/DOC1) affects only the complex integrity or the rate of substrate binding and processing [69,70]. SWM1 and CDC26 only have essential roles at restrictive temperatures in maintaining structural stability of the complex [26], whereas SWM1 and MND2 are essential during meiotic cell division [27]. In S. pombe, individual knockdowns of APC14 and APC15 did not display any abnormal phenotype but the cells developed a temperaturesensitive phenotype and chromosome segregation abnormalities when two proteins were mutated simultaneously or depleted with other APC components [47]. The fact that 7 out of 10 T. brucei APC/C subunits are dispensable for cell cycle progression could mean that they have redundant structural and functional roles with the other subunits. It may require double or multiple knockdowns of these subunits to inflict a detectable phenotype.

Despite all the apparent structural and functional uniqueness, $T$. brucei APG/C showed also some conserved functions as those observed in the other eukaryotes. The knockdowns of APC1, CDC27 and AP2 were each found to arrest the procyclic form T. brucei cells in metaphase, suggesting that the APC/C function is required for metaphase-anaphase transition. The $\mathrm{APC} / \mathrm{C}$ function is also needed for degradation of the mitotic cyclin $\mathrm{CycB} 2 /$ cyc6 during mitosis in $\mathrm{T}$. brucei. The degradation, essential for mitotic exit among the other eukaryotes [16,22], is mediated by the $26 \mathrm{~S}$ proteasome in $T$. brucei, which recognizes poly-ubiquitinated GycB2/cyc6 as substrate. This ubiquitination-dependent degradation is likely provided by the poly-ubiquitinating action of APC/

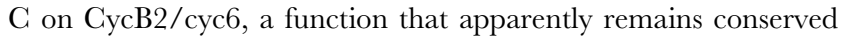
in $\mathrm{T}$. brucei.

We have thus characterized an APC/C in T. brucei that performs apparently both of the well-known functions during mitosis. But its unusually simple composition and the apparent functional redundancy among the 10 subunits distinguish it from the other APC/C's. The lack of an MCG mediated regulatory mechanism and the apparent absence of securin/Pdsl and CDC20 in T. brucei further demonstrates a significant discrepancy between $\mathrm{T}$. brucei APG/C and the others. The APC/C in $T$. brucei could be thus easily classified as a potential target for antitrypanosomiasis chemotherapy.

\section{Supporting Information}

Figure S1 Hydroxyurea (HU) synchronization of the cell cycle progression in $\boldsymbol{T}$. brucei. (A) Western blotting of TbCPC1-eYFP expression in TbAPC1-PTP cells. The same cell extract was immuno-probed with HPC4 antibody for PTP expression and anti-GFP antibody for eYFP expression. Asterisk indicates a non-specific anti-GFP immune-reactive band and upper and lower arrows indicate the positions of APC1 and CPC fusion proteins, respectively. (B) Flow cytometric analysis of hydroxyurea synchronized cells at $0,2.5$ and 4.5 hours after release. $(\mathbf{G})$ Fluorescence microscopic analysis of cells co-expressing APC1-PTP and CPC1.eYFP at S-phase (0 hr), metaphase $(2.5 \mathrm{hr})$ and anaphase $(4.5 \mathrm{hr})$ after hydroxyurea release. DIC, DAPI and YFP filters are shown with merge composite. Bars $=2 \mu \mathrm{M}$. (D) Quantitative microscopic analysis of eYFP 
signals. Approximately 200 cells from each sample were counted and data are presented as localization pattern of S-phase $(0 \mathrm{hr})$, metaphase $(2.5 \mathrm{hr})$ and anaphase $(4.5 \mathrm{hr})$ from two independent experiments.

(TIF)

Figure S2 Time courses of expression of APC1, GDC27, AP1 and AP2 in synchronized $T$. brucei growth. Cells expressing endogenous PTP fusion proteins of (A) APC1; (B) CDC27; (C) AP1 and (D) AP2 were arrested in late S-phase after $16 \mathrm{hr}$ treatment with $0.3 \mathrm{mM}$ hydroxyurea. Samples of the released cells were taken every hour and their lysates monitored for the expression of individual fusion proteins by immunoblotting using the HPC4 antibody with anti-tubulin antibody used as loading controls.

(TIF)

Figure S3 The RNAi knockdown of AP1 /APG4. (A) qPCR assay of the level of AP1/APC4 mRNA 72 hrs after the induction of AP1/APC4 RNAi. (B) The rate of cell growth was monitored for 7 days after the RNAi induction. $(\mathbf{C})$ N/K tabulations of the AP1/APC4-depleted cells on days $0,1,3$ and 5 after RNAi induction. (D) Flow cytometric analysis of DNA contents in AP1/ APC4-depleted cells. Little distinction was observed in the results from RNAi-induced and un-induced cells.

(TIF)

Figure S4 RNAi knockdown of AP3. Panels A, B, C and D are as described in Figure $\mathrm{S3}$.

(TIF)

Figure S5 Synchronization of the cell cycle progression in $\boldsymbol{T}$. brucei with hydroxyurea. Strain $29-13$ procyclic $T$. brucei cells expressing CycB2/cyc6-3HA were treated with $0.3 \mathrm{mM}$

\section{References}

1. Fenn K, Matthews KR (2007) The cell biology of Trypanosoma brucei differentiation. Curr Opin Microbiol 10: 539-546.

2. Hammarton TC (2007) Cell cycle regulation in Trypanosoma brucei. Mol Biochem Parasitol 153: 1-8.

3. McKean PG (2003) Coordination of cell cycle and cytokinesis in Trypanosoma brucei. Curr Opin Microbiol 6: 600-607.

4. Hammarton TC, Clark J, Douglas F, Boshart M, Mottram JC (2003) Stagespecific differences in cell cycle control in Trypanosoma brucei revealed by RNA interference of a mitotic cyclin. J Biol Chem 278: 22877-22886.

5. Kumar P, Wang CC (2006) Dissociation of cytokinesis initiation from mitotic control in a eukaryote. Eukaryot Cell 5: 92-102.

6. Tu X, Wang CG (2004) The involvement of two cdc2-related kinases (CRKs) in Trypanosoma brucei cell cycle regulation and the distinctive stage-specific phenotypes caused by CRK3 depletion. J Biol Chem 279: 20519-20528.

7. Hammarton TC, Monnerat S, Mottram JC (2007) Cytokinesis in trypanosomatids. Curr Opin Microbiol 10: 520-527.

8. Fededa JP, Gerlich DW (2012) Molecular control of animal cell cytokinesis. Nat Cell Biol 14: 440-447.

9. Glotzer M (2001) Animal cell cytokinesis. Annu Rev Cell Dev Biol 17: 351-386.

10. Li Z, Lee JH, Chu F, Burlingame AL, Gunzl A, et al. (2008) Identification of a novel chromosomal passenger complex and its unique localization during cytokinesis in Trypanosoma brucei. PLoS One 3: e2354.

11. Ersfeld K, Gull K (1997) Partitioning of large and minichromosomes in Trypanosoma brucei. Science 276: 611-614.

12. Barford D (2011) Structure, function and mechanism of the anaphase promoting complex (APC/C). Q Rev Biophys 44: 153-190.

13. Musacchio A, Salmon ED (2007) The spindle-assembly checkpoint in space and time. Nat Rev Mol Cell Biol 8: 379-393.

14. Peters JM (2006) The anaphase promoting complex/cyclosome: a machine designed to destroy. Nat Rev Mol Cell Biol 7: 644-656.

15. Pines J (2011) Cubism and the cell cycle: the many faces of the APC/C. Nat Rev Mol Cell Biol 12: 427-438.

16. van Leuken R, Clijsters L, Wolthuis R (2008) To cell cycle, swing the APC/C. Biochim Biophys Acta 1786: 49-59.

17. Cohen-Fix O, Peters JM, Kirschner MW, Koshland D (1996) Anaphase initiation in Saccharomyces cerevisiae is controlled by the APC-dependent degradation of the anaphase inhibitor Pds1p. Genes Dev 10: 3081-3093. hydroxyurea for 16 hours, washed twice in fresh medium and allowed to progress synchronously for 8 hours. The hourly cell samples were stained with propidium iodide, processed for flow cytometry and the FL2-A DNA peaks are presented. DNA contents $(2 \mathrm{C}$ or $4 \mathrm{C})$ were shown at the bottom.

(TIF)

Table S1 Identification by LG-MS/MS of APG/C subunit proteins. Protein components of the APC/C complex were identified by comparison of replicate LC-MS/MS peptide sequencing analyses. To be considered a candidate APC/C subunit, it was required that the protein was observed in all four cell cycle stages (G1, S-phase, Metaphase and Anaphase), that at least one experiment included a minimum of two unique peptides for confident protein identification, and that the protein was not observed in a control experiment.

(XLS)

\section{Acknowledgments}

We thank Drs D. Toczyski, P. Walter and D. Morgan at the University of California San Francisco for their generous gift of yeast wild type and APC/C mutant strains. Mass spectrometry analysis was performed in the Bio-Organic Biomedical Mass Spectrometry Resource at the University of California San Francisco (A.L. Burlingame, Director). We would also like to thank Chris Adams and the Stanford University Mass Spectrometry Core, for data acquisition and analysis of one of the MS data sets.

\section{Author Contributions}

Performed the LC-MS/MS: GK MB. Conceived and designed the experiments: CGW MB. Performed the experiments: MB GK. Analyzed the data: MB GK. Contributed reagents/materials/analysis tools: CCW ALB. Wrote the paper: MB CCW.

18. Funabiki H, Yamano H, Kumada K, Nagao K, Hunt T, et al. (1996) Cut2 proteolysis required for sister-chromatid seperation in fission yeast. Nature 381: $438-441$.

19. Stemmann O, Zou H, Gerber SA, Gygi SP, Kirschner MW (2001) Dual inhibition of sister chromatid separation at metaphase. Cell 107: 715-726.

20. Uhlmann F, Lottspeich F, Nasmyth K (1999) Sister-chromatid separation at anaphase onset is promoted by cleavage of the cohesin subunit Scc1. Nature 400: 37-42.

21. Amon A (1997) Regulation of B-type cyclin proteolysis by Cdc28-associated kinases in budding yeast. EMBO J 16: 2693-2702.

22. Amon A, Irniger S, Nasmyth K (1994) Closing the cell cycle circle in yeast: G2 cyclin proteolysis initiated at mitosis persists until the activation of $\mathrm{G} 1$ cyclins in the next cycle. Cell 77: 1037-1050.

23. Kumar P, Wang CC (2005) Depletion of anaphase-promoting complex or cyclosome (APC/C) subunit homolog APC1 or CDC27 of Trypanosoma brucei arrests the procyclic form in metaphase but the bloodstream form in anaphase. J Biol Chem 280: 31783-31791.

24. Bessat M, Ersfeld K (2009) Functional characterization of cohesin SMC3 and separase and their roles in the segregation of large and minichromosomes in Trypanosoma brucei. Mol Microbiol 71: 1371-1385.

25. Zachariae W, Shevchenko A, Andrews PD, Ciosk R, Galova M, et al. (1998) Mass spectrometric analysis of the anaphase-promoting complex from yeast: identification of a subunit related to cullins. Science 279: 1216-1219.

26. Hall MC, Torres MP, Schroeder GK, Borchers CH (2003) Mnd2 and Swm1 are core subunits of the Saccharomyces cerevisiae anaphase-promoting complex. J Biol Chem 278: 16698-16705.

27. Zachariae W, Shin TH, Galova M, Obermaier B, Nasmyth K (1996) Identification of subunits of the anaphase-promoting complex of Saccharomyces cerevisiae. Science 274: 1201-1204

28. Li Z, Wang CG (2003) A PHO80-like cyclin and a B-type cyclin control the cell cycle of the procyclic form of Trypanosoma brucei. J Biol Chem 278: 20652 20658.

29. Thornton BR, Ng TM, Matyskiela ME, Carroll CW, Morgan DO, et al. (2006) An architectural map of the anaphase-promoting complex. Genes Dev 20: 449460.

30. Mumberg D, Muller R, Funk M (1995) Yeast vectors for the controlled expression of heterologous proteins in different genetic backgrounds. Gene 156: $119-122$. 
31. Gietz RD, Schiestl RH (2007) High-efficiency yeast transformation using the LiAc/SS carrier DNA/PEG method. Nat Protoc 2: 31-34.

32. Gietz RD, Woods RA (2006) Yeast transformation by the LiAc/SS Carrier DNA/PEG method. Methods Mol Biol 313: 107-120.

33. Wirtz E, Leal S, Ochatt C, Cross GA (1999) A tightly regulated inducible expression system for conditional gene knock-outs and dominant-negative genetics in Trypanosoma brucei. Mol Biochem Parasitol 99: 89-101.

34. Li Z, Wang CC (2002) Functional characterization of the 11 non-ATPase subunit proteins in the trypanosome $19 \mathrm{~S}$ proteasomal regulatory complex. J Biol Chem 277: 42686-42693.

35. Schimanski B, Nguyen TN, Gunzl A (2005) Highly efficient tandem affinity purification of trypanosome protein complexes based on a novel epitope combination. Eukaryot Cell 4: 1942-1950.

36. Subramaniam C, Veazey P, Redmond S, Hayes-Sinclair J, Chambers E, et al. (2006) Chromosome-wide analysis of gene function by RNA interference in the african trypanosome. Eukaryot Cell 5: 1539-1549.

37. Chowdhury AR, Zhao Z, Englund PT (2008) Effect of hydroxyurea on procyclic Trypanosoma brucei: an unconventional mechanism for achieving synchronous growth. Eukaryot Cell 7: 425-428.

38. Chalkley RJ, Baker PR, Medzihradszky KF, Lynn AJ, Burlingame AL (2008) Indepth analysis of tandem mass spectrometry data from disparate instrument types. Mol Cell Proteomics 7: 2386-2398.

39. Elias JE, Gygi SP (2007) Target-decoy search strategy for increased confidence in large-scale protein identifications by mass spectrometry. Nat Methods 4: 207214.

40. Choi H, Fermin D, Nesvizhskii AI (2008) Significance analysis of spectral count data in label-free shotgun proteomics. Mol Cell Proteomics 7: 2373-2385.

41. Liu H, Sadygov RG, Yates JR 3rd (2004) A model for random sampling and estimation of relative protein abundance in shotgun proteomics. Anal Chem 76: 4193-4201.

42. Redmond S, Vadivelu J, Field MC (2003) RNAit: an automated web-based tool for the selection of RNAi targets in Trypanosoma brucei. Mol Biochem Parasitol 128: $115-118$

43. Bochud-Allemann N, Schneider A (2002) Mitochondrial substrate level phosphorylation is essential for growth of procyclic Trypanosoma brucei. J Biol Chem 277: 32849-32854.

44. Dong Y, Bogdanova A, Habermann B, Zachariae W, Ahringer J (2007) Identification of the $\mathrm{C}$. elegans anaphase promoting complex subunit Cdc26 by phenotypic profiling and functional rescue in yeast. BMC Dev Biol 7: 19 .

45. Nagy O, Pal M, Udvardy A, Shirras CA, Boros I, et al. (2012) lemmingA encodes the Apc11 subunit of the APC/C in Drosophila melanogaster that forms a ternary complex with the E2-C type ubiquitin conjugating enzyme, Vihar and Morula/Apc2. Cell Div 7: 9 .

46. Schwickart M, Havlis J, Habermann B, Bogdanova A, Camasses A, et al. (2004) Swm $1 /$ Apc13 is an evolutionarily conserved subunit of the anaphase-promoting complex stabilizing the association of Cdc16 and Cdc27. Mol Cell Biol 24: 3562-3576.

47. Yoon HJ, Feoktistova A, Wolfe BA, Jennings JL, Link AJ, et al. (2002) Proteomics analysis identifies new components of the fission and budding yeast anaphase-promoting complexes. Curr Biol 12: 2048-2054

48. Kops GJ, van der Voet M, Manak MS, van Osch MH, Naini SM, et al. (2010) APC16 is a conserved subunit of the anaphase-promoting complex/cyclosome. J Cell Sci 123: 1623-1633.

49. Kraft C, Herzog F, Gieffers C, Mechtler K, Hagting A, et al. (2003) Mitotic regulation of the human anaphase-promoting complex by phosphorylation. EMBO J 22: 6598-6609.
50. Peters JM (2002) The anaphase-promoting complex: proteolysis in mitosis and beyond. Mol Cell 9: 931-943.

51. Sherwin T, Gull K (1989) The cell division cycle of Trypanosoma brucei brucei: timing of event markers and cytoskeletal modulations. Philos Trans R Soc Lond B Biol Sci 323: 573-588.

52. Woodward R, Gull K (1990) Timing of nuclear and kinetoplast DNA replication and early morphological events in the cell cycle of Trypanosoma brucei. J Cell Sci 95 (Pt 1): 49-57.

53. Hershko A (1999) Mechanisms and regulation of the degradation of cyclin B. Philos Trans R Soc Lond B Biol Sci 354: 1571-1575; discussion 1575-1576.

54. Wirth KG, Ricci R, Gimenez-Abian JF, Taghybeeglu S, Kudo NR, et al. (2004) Loss of the anaphase-promoting complex in quiescent cells causes unscheduled hepatocyte proliferation. Genes Dev 18: 88-98.

55. Li Z, Zou CB, Yao Y, Hoyt MA, McDonough S, et al. (2002) An easily dissociated $26 \mathrm{~S}$ proteasome catalyzes an essential ubiquitin-mediated protein degradation pathway in Trypanosoma brucei. J Biol Chem 277: 15486-15498.

56. Mutomba MC, To WY, Hyun WC, Wang CC (1997) Inhibition of proteasome activity blocks cell cycle progression at specific phase boundaries in African trypanosomes. Mol Biochem Parasitol 90: 491-504.

57. Foe I, Toczyski D (2011) Structural biology: a new look for the APC. Nature 470: $182-183$

58. Barford D (2011) Structural insights into anaphase-promoting complex function and mechanism. Philos Trans R Soc Lond B Biol Sci 366: 3605-3624.

59. Schreiber A, Stengel F, Zhang Z, Enchev RI, Kong EH, et al. (2011) Structural basis for the subunit assembly of the anaphase-promoting complex. Nature 470: 227-232.

60. Lupas A, Baumeister W, Hofmann K (1997) A repetitive sequence in subunits of the $26 \mathrm{~S}$ proteasome and $20 \mathrm{~S}$ cyclosome (anaphase-promoting complex). Trends Biochem Sci 22: 195-196.

61. Hwang LH, Lau LF, Smith DL, Mistrot CA, Hardwick KG, et al. (1998) Budding yeast Cdc20: a target of the spindle checkpoint. Science 279: 10411044.

62. Visintin R, Prinz S, Amon A (1997) CDC20 and CDH1: a family of substratespecific activators of APC-dependent proteolysis. Science 278: 460-463.

63. Herzog F, Primorac I, Dube P, Lenart P, Sander B, et al. (2009) Structure of the anaphase-promoting complex/cyclosome interacting with a mitotic checkpoint complex. Science 323: 1477-1481.

64. Sudakin V, Chan GK, Yen TJ (2001) Checkpoint inhibition of the APG/C in HeLa cells is mediated by a complex of BUBR1, BUB3, CDC20, and MAD2. J Cell Biol 154: 925-936.

65. Gillett ES, Espelin CW, Sorger PK (2004) Spindle checkpoint proteins and chromosome-microtubule attachment in budding yeast. J Cell Biol 164: 535546.

66. Li R, Murray AW (1991) Feedback control of mitosis in budding yeast. Cell 66: 519-531.

67. Sikorski RS, Michaud WA, Wootton JC, Boguski MS, Connelly C, et al. (1991) TPR proteins as essential components of the yeast cell cycle. Cold Spring Harb Symp Quant Biol 56: 663-673.

68. Yu H, Peters JM, King RW, Page AM, Hieter P, et al. (1998) Identification of a cullin homology region in a subunit of the anaphase-promoting complex. Science 279: 1219-1222.

69. Carroll CW, Morgan DO (2002) The Doc1 subunit is a processivity factor for the anaphase-promoting complex. Nat Cell Biol 4: 880-887.

70. Passmore LA, McCormack EA, Au SW, Paul A, Willison KR, et al. (2003) Docl mediates the activity of the anaphase-promoting complex by contributing to substrate recognition. EMBO J 22: 786-796. 